\title{
Moisture Sources for Precipitation Variability over the Arabian Peninsula
}

\section{Matthew Horan ( $\nabla$ mhoran@vols.utk.edu )}

University of Tennessee System: The University of Tennessee System https://orcid.org/0000-00031024-5557

\section{Fulden Batibeniz}

ETH-Zürich

\section{Fred Kucharski}

ICTP: Abdus Salam International Centre for Theoretical Physics

\section{Mansour Almazroui}

King Abdulaziz University

\section{Muhammad Adnan Abid}

ICTP: Abdus Salam International Centre for Theoretical Physics Joshua Fu

UTK: The University of Tennessee Knoxville

\section{Moetasim Ashfaq}

ORNL: Oak Ridge National Laboratory

\section{Research Article}

Keywords:

Posted Date: December 9th, 2021

DOI: https://doi.org/10.21203/rs.3.rs-1136144/v1

License: (c) (1) This work is licensed under a Creative Commons Attribution 4.0 International License. Read Full License 


\title{
Moisture Sources for Precipitation Variability over the Arabian Peninsula
}

\author{
${ }^{1,2}$ Matthew F. Horan*, ${ }^{3}$ Fulden Batibeniz, ${ }^{4}$ Fred Kucharski, ${ }^{5,6}$ Mansour Almazroui, ${ }^{4}$ Muhammad Adnan
} Abid, ${ }^{1,2,7}$ Joshua S. Fu, ${ }^{1,2}$ Moetasim Ashfaq

${ }^{1}$ Computational Sciences and Engineering Division, Oak Ridge National Laboratory, Oak Ridge, Tennessee, United (1)

\author{
States \\ ${ }^{2}$ Bredesen Center, University of Tennessee, Knoxville, Tennessee, United States \\ ${ }^{3}$ Institute for Atmospheric and Climate Science, ETH Zurich, Zurich, Switzerland \\ ${ }^{4}$ Section of Earth System Physics, Abdus Salam International Centre for Theoretical Physics, Trieste, Italy \\ ${ }^{5}$ Department of Meteorology, King Abdulaziz University, Jeddah, Saudi Arabia \\ ${ }^{6}$ Climatic Research Unit, School of Environmental Sciences, University of East Anglia, Norwich NR4 7TJ, UK \\ ${ }^{7}$ Department of Civil and Environmental Engineering, University of Tennessee, Knoxville, Tennessee, United States
}

*Corresponding Author

Matthew Horan

mhoran@vols.utk.edu

This manuscript has been co-authored by employees of Oak Ridge National Laboratory, managed by UT Battelle, LLC, under contract DE-AC05-00OR22725 with the U.S. Department of Energy. The publisher, by accepting the article for publication, acknowledges that the United States Government retains a non-exclusive, paid-up, irrevocable, world-wide license to publish or reproduce the published form of this manuscript, or allow others to do so, for United States Government purposes. The Department of Energy will provide public access to these results of federally sponsored research in accordance with the DOE Public Access Plan (http://energy.gov/downloads/doe-public-accessplan). 
We apply a Lagrangian-based moisture back trajectory method on two reanalysis datasets to 37 determine the moisture sources for wet season precipitation over the Arabian Peninsula, defined as land on the Asian Continent to the south of the Turkish border and west of Iran. For this purpose, we make use of evaporative source region between $65^{\circ} \mathrm{W}-120^{\circ} \mathrm{E}$ and $30^{\circ} \mathrm{S}-60^{\circ} \mathrm{N}$ which is divided into twelve sub-regions. Our results indicate a north to south spatiotemporal heterogeneity in the

41 characteristics of dominant moisture sources. In the north, moisture for precipitation is mostly 42 sourced from European land and major water bodies, such as Mediterranean and Caspian Seas. Areas further south dependent on moisture transport from the Western Indian Ocean and parts of 44 the African continent. El Nino Southern Oscillation cycle (ENSO) oscillation exhibits an overall positive but sub-seasonally varying influence on the precipitation variability over the region with mostly positive moisture anomalies form all major source regions. A significant drying trend exists over parts of the Peninsula, which is partly attributed to anomalies in the moisture advection from the Congo Basin and South Atlantic Ocean. However, precipitation trends over the terrestrial part of evaporative source region vary across observations and reanalysis datasets, which warrants the need for additional modeling studies to further our understanding in the identification of key 51 processes contributing to the negative trends. 


\section{Introduction}

The Arabian Peninsula (AP) exhibits arid climate characteristics (Abdullah and Almazroui, 1998; Almazroui, 2011; Almazroui et al. 2012; Edgell, 2006) with limited freshwater resources, a fragile ecosystem, and fossil fuels driven economies. More than $75 \%$ of the annual precipitation over the region is received between November and April (Abduallah and Almazroui, 1998; Almazroui, 2012; Almazroui et al 2012), which is also known as the wet season. Recent decades have witnessed statistically significant warming and reduced precipitation trends across the AP (Almazroui et al., 2012), which are precursors of water cycle intensification. These changes in the regional climate characteristics are causing an increase in desertification that has the potential to effect biodiversity and socioeconomic stability in the region. While the anthropogenic footprint is the likely cause of recent trends in regional hydrological cycle, slow varying climate forcing, such as sea surface temperatures, are also known to have an influence in the precipitation variability over the region. More specifically, studies show that both wet and dry extremes over the AP can be related to sea surface temperatures variability in the central-eastern equatorial Pacific region (Kang et al..2015). Similarly, wetter (drier) than normal wet season is experienced over AP during the El Nino or positive (La Nina or negative) phase of the El Nino Southern Oscillation (ENSO) (Abid et al. 2016; Atif et al. 2020). Previous studies also indicate a moderate and statistically insignificant influence of the North Atlantic Oscillation where the region may experience a drier (wetter) than normal wet season over northern and western portions of the AP during the positive (negative) phase of the North Atlantic Oscillation (NAO;Atif et al. 2020; Donat et al. 2014; Ehsan et al, 2017; Saeed and Almazroui, 2019 
Even though a general understanding of climate characteristics of the AP exists, there

87 remains several gaps in our understanding of factors impacting wet season precipitation variability. For instance, it is relatively unknown which terrestrial and oceanic evaporative sources provide moisture to the region during the wet season. Few studies suggest that much of the rainfall over the northern AP can be attributed to extratropical cyclones from the Mediterranean (Almazroui et al. 2016), and that moisture flux from the Mediterranean over eastern Africa provides rainfall over the Ethiopian highlands (Viste and Sorteberg, 2013).

However, an explicit identification of moisture sources for the wet season precipitation over the AP is yet to be established. Similarly, thermodynamic pathways through which natural modes of climate variability, such as ENSO, exert their influence on precipitation distribution over the AP have not been clearly understood. Likewise, no mechanistic understanding exists regarding the thermodynamic factors influencing prevailing precipitation trends over the region. Therefore, this study aims to improve our understanding of AP climate by addressing knowledge gaps in the above three aspects.

Three physical sources including moisture already present in the atmospheric column, moisture advected into the region, and moisture sourced through local evapotranspiration, facilitate precipitation over a region (Batibeniz et al. 2020; Brubaker et al. 1993; Burde and Zangvil 2001; Ciric et al. 2018; Dominguez et al. 2006; Dominguez and Kumar 2008; Drumond et al. 2011; Eltahir and Bras 1996; Gómez-Hernández et al. 2013; Schicker et al. 2010; Trenberth 1999). Most commonly, the moisture flow over or from a region is either studied by observing the spatiotemporal trajectories of moist air parcels, also known as Lagrangian approach, or by observing the moisture in-and outfluxes at fixed positions, also known as Eulerian approach. The Lagrangian-based moisture back trajectory analyses is the most used approach due to its 
relatively better accuracy in determining moisture sources and sinks (Gimeno et al. 2012; Gimeno et al. 2020; Nieto et al. 2006; Sodemann et al. 2008).

As previously noted, in this study, we aim to investigate the thermodynamic drivers of spatiotemporal distribution of precipitation and its variability during the wet season over the AP. For this purpose, we employ a Lagrangian moisture tracking algorithm to identify major evaporative sources at climatological scale, variation of their moisture contribution at interannual and intra-seasonal timescales, and during positive and negative phases of ENSO and NAO. The details of data and moisture tracking analyses is provided in Section 2. Section 3 describes main results and discussion of these analysis. Section 4 summarizes key findings and proposes future research directions.

\section{Data and Methods}

\subsection{Data}

We use two reanalysis datasets, the Modern-Era Retrospective Analysis for Research and Application Version 2 (MERRA-2, Gelaro et al. 2017), available at $0.5^{\circ} \times 0.625^{\circ}$ horizontal grid spacing, and the European Reanalysis version 5 (ERA5; Herschbach et al. 2020), available at $0.25^{\circ} \times 0.25^{\circ}$ horizontal grid spacing. The use of multiple datasets is to ensure robust understanding of moisture sources over the study region. The ERA5 dataset is remapped to the MERRA-2 horizontal grid before its use. From these datasets, we obtained four variables: daily evapotranspiration, daily precipitation, six-hourly vertically integrated eastward moisture flux, and six-hourly vertically integrated northward moisture flux.

Given that reanalyzed and observed precipitation are often not in high correspondence at daily timescale, we make use of reanalyzed precipitation in our analyses for it to be consistent with the reanalyzed moisture fluxes and evapotranspiration used in the determination of moisture 
132 pathways. While this methodological choice is necessary for accuracy in the calculation of

133 moisture trajectories, it may lead to inaccuracies in the identification of moisture sources if

134 spatial distribution of precipitation substantially varies between reanalyzed and observed.

135 Therefore, precipitation from the two reanalysis is compared with several gridded observations

136 to understand the degree of uncertainty associated with our methodological choice. The

137 observations include data from the University of East Anglia Climatic Research Unit (CRU;

138 Harris et al. 2013), NOAA’s Precipitation Estimation from Remotely Sensed Information using

139 Artificial Neural Networks (PERSIANN; Sorooshian et al. 2014; Ashouri et al. 2015), the Global

140 Precipitation Climatology Centre monthly precipitation dataset (GPCC; Schneider et al. 2016),

141 and the Climate Hazards Group InfraRed Precipitation with Station dataset (CHIRPS; Funk et al.

142 2015). All observational datasets are also remapped to match the MERRA-2 grid spacing. Note

143 that not all observations fully span our analyses period that covers 1980 to 2019, as PERSIANN

144 (GPCC) is not available for 1980-1982 (2017-2019).

145

146

147

148

149

150

151

152

153

154

\subsection{Moisture back-trajectory analyses}

We make use of evaporative source region between $65^{\circ} \mathrm{W}-120^{\circ} \mathrm{E}$ along the longitudes and $30^{\circ} \mathrm{S}-60^{\circ} \mathrm{N}$ along the latitudes for moisture back trajectory analyses over the AP. The source region is divided into 12 sub-regions, as depicted in Figure 1. The sub-division broadly separates known oceanic basins and large water bodies to ensure relatively accurate attribution of precipitation over the study region to remote sources. Most subdivision of terrestrial regions are based on the homogeneity of precipitation seasonality within a sub-region during the November to April season, such as Central/Western Asia, Europe, Northern Africa, Eastern Africa. Regions such as East Asia are separated from the rest as little contribution is expected from there due to its downstream location. These sub-regions include the AP as target region (1; Asian Continent 
west of Iran and South of Turkey), Northern Africa (2; African continent north of $\left.20^{\circ} \mathrm{N}\right)$, Europe land (3; all European countries including portions of Turkey and Russia in Asia), North Atlantic Ocean (4; areas west of Europe/Africa North of $\left.20^{\circ} \mathrm{N}\right)$, the Mediterranean and Caspian Seas (5; all water bodies between $5^{\circ} \mathrm{W}$ to $65^{\circ} \mathrm{E}$ and $29^{\circ} \mathrm{N}$ to $50^{\circ} \mathrm{N}$ ), South Atlantic Ocean (6; Atlantic ocean west of African continent and south of $\left.20^{\circ} \mathrm{N}\right)$, East Asian land (7; Asian land outside Russia and Turkey that is not in regions 1 or 10), Western Indian Ocean (8; Indian Ocean between $30^{\circ} \mathrm{E}$ to $80^{\circ} \mathrm{E}$ and south of $\left.31^{\circ} \mathrm{N}\right)$, Eastern Indian Ocean (9, Indian Ocean east of $\left.80^{\circ} \mathrm{E}\right)$, western and central Asia land (10; Asian continent between $40^{\circ} \mathrm{E}$ to $80^{\circ} \mathrm{E}$ and $25^{\circ} \mathrm{N}$ to $45^{\circ} \mathrm{N}$ not part of regions 1 or 3), western Africa land (11; African continent south of $20^{\circ} \mathrm{N}$ and west of $\left.22.5^{\circ} \mathrm{E}\right)$, and eastern Africa land (12; African continent south of $20^{\circ} \mathrm{N}$ and east of $\left.22.5^{\circ} \mathrm{E}\right)$. Note that the study region defined in our analyses as the AP includes northern parts of Iraq and Syria that are formally not considered a part of the Peninsula.

For this study, we employ a Lagrangian-based Dynamic Recycling Model (DRM), like that implemented over the Mediterranean by Batibeniz et al (2020), and over South Asia by Ashfaq et al. (2017) and Mei et al. (2015). This model was originally developed by Dominguez et al (2006), which was modified to not include the reliance on parameterization (Dominguez et al. 2006; Gimeno et al. 2012; Stohl 2005) and has been detailed in Mei et al (2015). Note that it assumes a well-mixed atmosphere and therefore makes use of vertically integrated moisture flux, which may be an issue over regions with strong vertical wind shear. However, this assumption should not be a concern in this study, as the atmosphere above the AP does not exhibit strong shear environment during the wet season. Also, note that the use of data assimilation in reanalysis may lead to a violation of moisture conservation assumption, however, Dominguez et al (2006) note that any correction for this assumption not being followed has little impact on the 
178 results. We implement our analysis from 15 October through 30 April continuously. The first 15-

179 days are discarded as those account for the residence time of moisture vapor in the atmosphere.

180 Our analyses span over 39 seasons, starting with the wet season from 1 November 1980 to 30

181 April 1981 and ending with the wet season from 1 November 2018 to 30 April 2019.

183 We investigate changes in precipitation variability caused by ENSO and NAO along with the 184 changes in moisture sources associated with these teleconnections. ENSO is defined based on the 185 standardized Nino 3.4 index, which is the area averaged detrended sea surface temperature 186 anomaly over the equatorial Pacific Ocean $\left(5^{\circ} \mathrm{S}\right.$ to $5^{\circ} \mathrm{N}, 170^{\circ} \mathrm{W}$ to $\left.120^{\circ} \mathrm{W}\right)$. NAO is defined as 187 the standardized principal component of the first EOF of the detrended sea level pressure over 188 the North Atlantic $\left(20^{\circ} \mathrm{N}\right.$ to $80^{\circ} \mathrm{N}, 90^{\circ} \mathrm{W}$ to $\left.40^{\circ} \mathrm{E}\right)$. These standardized indices are regressed onto 189 the anomalies of sourced moisture from individual and aggregated source regions over the AP, as 190 well as with the anomalies of $850 \mathrm{mb}$ winds over the evaporative source region.

\section{Results and Discussion}

\subsection{Reanalyzed versus observed precipitation}

First, we address the question that how comparable precipitation distribution is between the 195 reanalysis and the observations (Fig. 2). At the annual time-scale, relatively high magnitudes of 196 precipitation exist along the Zagros Mountains in the north, and over Asir and Sarat mountains in

197 the southwest. These precipitation hot spots are present in all datasets, however, their strength 198 over the southwestern AP is relatively weak in CHIRPS. All maxima are relatively stronger in 199 ERA5 while CRU and PERSIANN tend to be wetter over Yemen and Oman. The precipitation 200 distribution over central Saudi Arabia is comparable across all datasets with CRU being the 
201 driest among all. Overall, there are no distinct or systematic differences between reanalyzed and 202 observed precipitation datasets. We further compare the percentage of annual precipitation that 203 falls during the wet season across datasets (Fig. S1). The purpose of this comparison is twofold. 204 First, we would like to ensure that there are no noticeable systematic differences in the intra205 annual distribution of precipitation between the reanalyzed and observed datasets. Second, we 206 want to highlight the fact that November to April season, used in this study, covers most of the

207 annual precipitation that falls over the region. Both observational and reanalyzed datasets show 208 that over $75 \%$, and in most cases over $90 \%$ of the precipitation, is received during the wet 209 season. The Red Sea Coast and Asir mountains receive considerable precipitation through warm season convection (Almazroui, 2011), which is reflected in relatively lower (30-60\%) fractions

211 during the wet season. There is discrepancy among the datasets pertaining to the wet season 212 contribution over parts of Yemen and Oman. This location however is in the Empty Quarter 213 where seasonal precipitation is very low and small differences can lead to higher fractional 214 changes. Overall, these comparisons suggest that there are no distinguishable systematic 215 differences in reanalyzed and observed precipitation distributions. Therefore, possibility of 216 unreliable determination of moisture sources based on the use of reanalyzed precipitation in our 217 analyses is quite remote.

\section{3.2.Characteristics of major moisture sources}

219 The fraction of moisture falling as precipitation in a specific grid cell that originated as 220 evapotranspiration from the entire evaporative source region (Fig. 1), also known as recycling 221 ratio, is shown in Figure 3a as an average of two datasets (ERA5 and MERRA2). At a grid point, 222 the highest recycling ratio is obtained when all the precipitation is sourced back to its origin. In 223 our case, recycling ratio varies between 90 to $96 \%$ (expressed in \% of the total) over most of the 224 AP, reflecting that the evaporative source domain used in this study is sufficiently large to 
225 account for the origin of almost all precipitation falling over the AP during the wet season. The

226 contribution from most prominent (all) source regions is shown in Figure 3 (Fig. S2) as an

227 average of recycling ratio based on two reanalysis datasets, while Figures S3 and S4 show

228 individual contributions from all regions separately for ERA5 and MERRA2, respectively. In the

229 north, most of the moisture comes from the Mediterranean/Caspian Seas (up to 50\%), North

230 Atlantic, and Europe (up to 40\%). The influence of these moisture sources progressively

231 diminishes towards the central to southern AP. In the central parts of AP, moisture advection

232 from the African continent and south Atlantic has sizeable contribution (up to $30 \%$ when

233 aggregated), while moisture transport from the western Indian Ocean dominates the southern half

234 of the AP (30 to 65\%). It is important to note that the geographical footprint of moisture from the

235 western Indian Ocean, which also includes Arabian and Red Seas, is the largest with maxima

236 over the southwestern tip of Yemen $(\sim 65 \%)$ and minima over the Zagros Mountains along the

237 border of Turkey in the north $(\sim 5 \%)$. Interestingly, local recycling of moisture does not have a

238 major role in the precipitation distribution over the AP, as its maximum contribution remains less

239 than $\sim 10-15 \%$. The relative contribution of individual evaporative sources is quite comparable

240 between ERA5 and MERRA2, reflecting little sensitivity to the choice of reanalysis in the

241 determination of moisture source regions. Due to this close correspondence between the two

242 datasets, we present rest of the analyzed results based on their average.

There is considerable intra-seasonal variability in moisture contribution from individual

244 source regions (Fig. 4). The contribution from Mediterranean/Caspian Seas is the highest until

245 the start of March when it gradually starts diminishing. Note that the northern part of the AP,

246 where Mediterranean/Caspian Seas have the most significant contribution, receives relatively

247 less rainfall towards the end of the rainy season (Fig. S5). On the other hand, the moisture 
248 contribution from the western Indian Ocean gradually strengths and reaches its maxima towards

249 the end of the rainy season, which is consistent with relatively large amounts of rainfall in March

250 and April over the southern half of the AP (Fig. S5). The intra-seasonal variability in the

251 contribution from eastern Africa is quite in sync with that from western Indian Ocean. Note that,

252 over this period, monsoon gradually moves southward and back over eastern Africa (Ashfaq et

253 al., 2021), which is substantially influenced by the Indian Ocean variability (Spinks and Lin,

254 2014). Some syncing is also noticed between moisture from Mediterranean/Caspian Seas and

255 North Atlantic, which is understandable as same atmospheric dynamics influences the

256 movements of storm tracks and moisture from Mediterranean and beyond (Batibeniz et al.,

257 2020). However, it is interesting to note that moisture contribution from Europe gradually

258 increases over the wet season and reaches its maxima at a time when moisture supply from North

259 Atlantic, Mediterranean/Caspian Seas depletes.

260 3.3.Thermodynamic pathways of ENSO/NAO influence over the AP

ENSO exhibits positive association with precipitation variability over the AP, meaning

262 that more rains are expected during the wet season when warm phase of ENSO is active and vice

263 versa (Abid et al. 2016; Atif et al. 2020). While earlier studies suggest above normal moisture

264 advection from the Indian Ocean during El Nino (Abid et al. 2020; Abid et al. 2018; De Vries et

265 al. 2016), more specific understanding of anomalies in moisture from oceanic and terrestrial

266 moisture source regions is yet to be determined. Our analyses suggests that ENSO enhances the

267 moisture influx over the AP from almost every source region during the positive phase of ENSO

268 (Figs. 5, S6). In particular, a statistically significant increase in moisture advection from the

269 Indian Ocean and African continent occurs. Note that Walker circulation disruption during El

270 Nino causes anomalous convection (subsidence) in the western (eastern) Indian Ocean (Abid et 
271 al. 2020). As a results, an anomalous westward flow emerges over the Indian Ocean in the lower

272 atmosphere, which is reflected in the regressed $850 \mathrm{mb}$ winds map (Fig. 5a). These conditions

273 favor enhanced moisture advection from the Indian Ocean, and northern parts of eastern Africa.

274 Moreover, wetter than normal conditions are well known over equatorial and eastern Africa

275 during the warm phase of ENSO (Mbigi and Xiao, 2021) and more moisture is available to be

276 transported to the AP. An excessive moisture transport is also witnessed from Europe and

277 Mediterranean/Caspian Seas, however, most of these increases are not statistically significant.

278 Local recycling also exhibits a significant increase over Iraq and Saudi Arabian region along the

279 Arabian Gulf (Fig. S6).

Substantial intra-seasonal variability in moisture anomalies from individual source

281 regions exists during ENSO (Figs. S8-S10). Overall, ENSO teleconnection becomes insignificant

282 and reverses over Iraq and adjacent Saudi Arabia region in Jan-Feb creating a reversal in

283 moisture anomalies from major source regions (Europe, North Atlantic and

284 Mediterranean/Caspian Seas). The circulation anomalies in the lower atmosphere (850mb)

285 exhibit an anomalous dry air entrainment from northern Africa during Jan-Feb in contrast to the

286 rest of season where moisture advection from abovementioned source regions is favored (Figs.

287 S8-S10). At individual level, the increase in contribution from eastern Africa and western Indian

288 Ocean is statistically more robust during Nov-Feb while that from South Atlantic only becomes

289 significant during Mar-Apr. Note that near the equatorial belt over east Africa ENSO

290 teleconnections lead to onshore wind anomalies from Indian Ocean and winds over land

291 changing direction in Mar-Apr, which limits the moisture advection from these regions to the

292 AP (Figure S10). 
As previously noted, NAO influence on the AP climate is not as robust as it is in the case

of ENSO. A positive phase of NAO causes the westerlies over the Mediterranean and Northern Africa to weaken, decreasing the amount of moisture that advects from Europe and the North

296 Atlantic into the target region. Spatially, the moisture change from the NAO teleconnection

297 exhibits a dipolar pattern over the AP, with negative association in the northern two thirds and

298 positive association in the southern one third. However, most of the negative influence over that

299 region is statistically insignificant (Fig. 6a) due to a lack of robustness in moisture anomalies

300 form the major source regions (Fig. 6b-6d). More specifically, the negative association in the 301 northern two thirds is associated with reduced moisture advection from Europe and North

302 Atlantic. While the moisture advection from Mediterranean/Caspian Seas also decreases

303 significantly over parts of central Saudi Arabia, its reduction is insignificant over Syria whereas

304 it shows a mixed response over Iraq. The positive association over the parts of southern AP is

305 due to an enhanced moist advection from western African, Indian Ocean and eastern Africa, and

306 more local recycling (Fig. S6). The effects of NAO teleconnection over the AP also exhibits

307 intra-seasonal variability (Figs. S11-S13). For instance, the statistically significant negative NAO

308 association over the central AP only exists during Nov-Dec where moisture supply from most of

309 the prominent sources shows a decrease. Similarly, increase in moisture advection from Indian

310 Ocean and parts of Africa over the southern AP is only significant in Mar-Apr.

\section{3.4. Wet season precipitation trends}

312 We use Mann-Kendall test for the calculation of trends in total precipitation and moisture 313 contribution from individual evaporative sources and test their significance at $95 \%$ confidence

314 level. Generally, the wet season precipitation over the AP exhibits negative trends (Fig. S14).

315 However, substantial agreement does not exist across datasets (observations/reanalysis) in the 
spatiotemporal distribution as well as the significance of these trends. Areas with most agreement are Zagros Mountains in northern Iraq and Syria, Asir and Sarat mountains ranges in southwestern Saudi Arabia and Yemen, and Najd in central Saudi Arabia, where precipitation exhibits negative trends (Fig. S14). In reanalysis datasets, these trends are consistent and significant over the southwestern and central parts of the AP, while agreement is low over Zagros Mountains where negative (but insignificant) trends are only present in ERA5. Based on 322 the trends in moisture advection from individual source regions (Fig. 7), it is apparent that the 323 negative trends over the central and southwestern AP (Fig. S14) are mostly driven by reduced 324 moisture advection from western Africa, south Atlantic, western Indian Ocean, and eastern Africa (ordered from most to least important). When trends are analyzed over the terrestrial parts 326 of the evaporative source region, both ERA5 and MERRA2 display significant strong negative 327 trends over the Congo basin and parts of central Africa (Fig. S15) - the region which is 328 partitioned as western Africa in our subdivision of moisture sources (Fig. 1). This region 329 experiences dry season between Nov to March (Ashfaq et al., 2021), which is why moisture 330 contribution from western Africa gradually increases during the wet season over the AP (Fig. 4; 331 mustard line). Studies have shown that dry season length has increased over this region in the 332 recent times (Froidurot and Diedhiou, 2017), which would limit moisture contribution from this 333 region to the AP. However, it is important to note that drying pattern seen in both reanalysis is 334 only replicated in CHIRPS and to some extent in PERSIANN, while CRU exhibits mostly 335 positive and GPCC exhibits strong positive trends. As previously noted, the moisture 336 contribution from the eastern African region also exhibits a decline over the southwestern AP, 337 which is present in both reanalyses (Figs. S16, S17). This reduction in moisture supply from eastern African is most likely due to drying trend over the Ethiopian highlands, which is present 
339 in both datasets. The negative trend over the Ethiopian highlands in also present in most of the 340 gridded observations (Fig. S14). Despite the noticeable differences between the reanalysis and

341 observations is the spatial distribution of precipitation trends over the evaporative source region,

342 the dependence of AP precipitation on the terrestrial evaporative sources demonstrates that how

343 precipitation trends over one source region can impact its distribution over a distant sink region

344 and highlight the complexity and intricacy of thermodynamic drivers impacting the precipitation

345 variability over a region.

346

347 4. Summary and Conclusions

348 An arid region like the AP primarily receives moisture through advection from other sources.

349 Except for the northern parts of the AP where Mediterranean storms bring moisture from the

350 Mediterranean Sea, North Atlantic and Europe over the region, the rest of the AP receives most

351 of the moisture from the western Indian Ocean with some contribution from the African

352 continent. The influence of the western Indian Ocean over the AP shows a gradient in the

353 contribution from west-southwest to north (Figs 3, S2-S4). Precipitation distribution varies

354 spatially during the wet season over the AP, which is driven by the presence of an intra-seasonal

355 variability in moisture sources. Perhaps, it is this intra-seasonal variation in moisture advection

356 from various sources that is the cause of lack of persistence in the ENSO and NAO

357 teleconnections during the wet season, which may result into the limited precipitation prediction

358 skill over the region (Abid et al. 2016; Ehsan et al. 2017). Therefore, it is worthwhile to revisit

359 the precipitation predictability over the region by considering the models ability in representing

360 the moisture sources and by identifying its relationship with seasonal prediction skill. Moisture

361 source anomalies may also act as predictors for the regional precipitation on sub-seasonal to

362 seasonal time scale during the wet season. 
Lack of consistency among the datasets regarding long-term trends is an issue that requires some attention. There is more consistency between the two reanalysis datasets than that among the observations or between the observations and reanalysis. The accuracy of datasets is imperative for precise attribution of prevailing precipitation trends. If precipitation trends over

367 the AP and the central/west Africa are indeed accurate in the two reanalysis, it implies that the 368 processes at play in the variability of AP climate are complex. Note that Congo basin and 369 adjacent areas are heavily influenced by moisture transport from the tropical South Atlantic (Sori 370 et al., 2017), and both regions exhibit a negative trend in moisture contribution to the AP. 371 Therefore, it is not unrealistic to assume that South Atlantic is one of the main players in the 372 negative precipitation trends over the parts of southwestern and central AP through its direct and 373 indirect (via Congo basin) influences on the AP climate. We also note that the collective 374 maximum moisture contribution from these two regions (western Africa and South Atlantic) over 375 any part of the AP is not more than 15-20\% of the total, however, substantial reduction in 376 moisture supply from these areas can still have a significant impact on the AP climate.

377 Overall, this study furthers our knowledge of the thermodynamic processes leading to wet 378 season precipitation over the AP. More specifically, it provides new insights regarding the 379 thermodynamic structure of climate over the AP, its intra-seasonal and interannual variability, 380 and pathways taken by important modes of climate variability (ENSO, NAO) impacting this 381 region. A significant fraction of moisture over the AP is transported from the terrestrial source 382 regions (African and European continent), which suggests that climate variability in those 383 regions has the potential to impact the precipitation distribution over the AP. Nonetheless, there 384 are still several gaps in our understanding towards such interdependencies of terrestrial climates 385 which warrant further studies in this area. The inconsistency in trends between multiple 
386 observational datasets leaves some uncertainties in our conclusions, which should also spark

387 further studies to test the validity of thermodynamic pathways, identified in our analyses,

388 through numerical model experiments. Note that we only analyzed the direct pathways through

389 which ENSO and NAO exert their influence on the AP precipitation variability. However,

390 teleconnections of natural modes of variability, particularly ENSO, are often a result of multiple

391 pathways such as those through inter-basin interactions (Abid et al., 2020). Therefore, further

392 investigations are needed to fully unravel the physical mechanisms responsible for these

393 teleconnections. Despite these caveats, this study has enhanced knowledge towards precipitation

394 variability in the region and the thermodynamic processes leading to it.

395

396 


\section{References}

Abdullah MA, Al-Mazroui M (1998) Climatological study of the southwestern region of Saudi Arabia. I. Rainfall Analysis. Clim Res. 9:213-223 https://www.jstor.org/stable/24864531

Abid MA, Kucharski F, Almazroui M, Kang, IS (2016) Interannual rainfall variability and ECMWF-Sys4-based predictability over the Arabian Peninsula winter monsoon region. Q.J.R. Meteorol. Soc. 142: 233-242. https://doi.org/10.1002/qj.2648

Abid MA, Almazroui M., Kucharski F, O’Brien E, Yousef AE (2018) ENSO relationship to summer rainfall variability and its potential predictability over Arabian Peninsula region. Npj Climate and Atmospheric Science 1(1). https://doi.org/10.1038/s41612-017-0007-3

Abid MA, Ashfaq M, Kucharski F, Evans, KJ, Almazroui M (2020). Tropical Indian Ocean mediates ENSO influence over Central Southwest Asia during the wet season. Geophys Res Lett 47:e2020GL089308. https://doi.org/10.1029/2020GL089308

Almazroui M (2012) Calibration of TRMM rainfall climatology over Saudi Arabia during 19982009. Atmos. Res. 99: 400-414 https://doi.org/10.1016/j.atmosres.2010.11.006

Almazroui M, Islam MN, Athar H, Jones PD, Rahman MA (2012) Recent climate change in the Arabian Peninsula: annual rainfall and temperature analysis of Saudi Arabia for 19782009. Int J Climatol 32:953-966. https://doi.org/10.1002/joc.3446

Almazroui M, Kamil S, Ammar K., Keay K, Alamoudi AO (2016) Climatology of the 500-hPa mediterranean storms associated with Saudi Arabia wet season precipitation. Clim Dyn 47:3029-3042 https://doi.org/10.1007/s00382-016-3011-0

Ashfaq M, Cavazos T, Reboita MS, Torres-Alavez JA, Im ES, Olusegun CF, Alves L, Key K, Adeniyi MO, Tall M, Sylla MB, Mehmood S, Zafar Q, Das S, Diallo I, Coppola E, Giorgi F (2021) Robust late twenty-first century shift in the regional monsoons in RegCM-CORDEX simulations. Clim Dyn 57:1463-1488, https://doi.org/10.1007/s00382020-05306-2

Ashfaq M, Rastogi D, Mei R, Touma D, Leung R (2017) Sources of errors in the simulation of South Asian monsoon in CMIP5 GCMs. Clim Dyn, 49:193-223 doi: 10.1007/s00382016-3337-7

Ashouri, H, Hsu K, Sorooshian S, Braithwaite DK, Knapp KR, Cecil LD, Nelson BR, Pratt OP, (2015) PERSIANN-CDR: Daily Precipitation Climate Data Record from Multisatellite Observations for Hydrological and Climate Studies. Bulletin of the American Meteorological Society 96(1):69-83. https://doi.org/10.1175/BAMS-D-13-00068.1

Atif RM, Almazroui M, Saeed S, Abid MA, Islam MN, Ismail M (2020) Extreme precipitation events over Saudi Arabia during the wet season and their associated teleconnections. Atmospheric Research 231:104655. https://doi.org/10.1016/j.atmosres.2019.104655

Batibeniz F, Ashfaq M, Önol B, Turuncoglu U, Mehmoud S, Evans K (2020) Identification of major moisture sources across the Mediterranean Basin. Clim Dyn 54:4109-4127 https://doi.org/10.1007/s00382-020-05224-3

Brubaker KL, Entekhabi D, Eagleson PS (1993) Estimation of continental precipitation recycling. J Clim 6:1077-1089. https://doi.org/10.1175/15200442(1993)006\%3c1077:EOCPR\%3e2.0.CO;2,

Burde GI, Zangvil A (2001) The estimation of regional precipitation recycling. Part I: review of recycling models. J Clim 14:2497-2508. https://doi.org/10.1175/15200442(2001)014<2497:TEORPR>2.0.CO;2 
Ciric D, Nieto R, Losada L, Drumond A, Gimeno L (2018) The Mediterranean Moisture Contribution to Climatological and Extreme Monthly Continental Precipitation. Water 10:519. https://doi.org/10.3390/w10040519,

De Vries AJ, Feldstein SB, Riemer M, Tyrlis E, Sprenger M, Baumgart M, Fnais M, Lelieveld J (2016) Dynamics of tropical-extratropical interactions and extreme precipitation events in Saudi Arabia in autumn, winter and spring. Q J R Meteorol Soc 142(697):1862-1880. https://doi.org/10.1002/qj.2781

Dominguez F, Kumar P (2008) Precipitation recycling variability and ecoclimatological stability — a study using NARR data. Part I: Central U. S. Plains Ecoregion. J Clim 21:5165-5186. https://doi.org/10.1175/2008JCLI1756.1

Dominguez F, Kumar P, Liang X-Z, Ting M (2006) Impact of atmospheric moisture storage on precipitation recycling. J Clim 19:1513-1530. https://doi.org/10.1175/JCLI3691.1,

Donat MG, Peterson TC, King AD, Almazroui M, Kolli RK, Boucherf D, Al-Mulla AY, Nour AY, Aly AA, Nada TAA, Semawi MM, Al Dashti HA, Salhab TG, El Fadli KI, Muftah MK, Eida SD, Badi W, Driouech F, El Rhaz K, Abubbaker MJY, Al Dhanhani JS, Al Shekaili MN (2014) Changes in extreme temperature and precipitation in the Arab region: long-term trends and variability related to ENSO and NAO. Int J Climatol 34:581-592. https://doi.org/10.1002/joc.3707,

Drumond A, Nieto R, Hernandez E, Gimeno L (2011) A Lagrangian analysis of the variation in moisture sources related to drier and wetter conditions in regions around the Mediterranean Basin. Nat Hazards Earth Syst Sci 11:2307-2320. https://doi.org/10.5194/nhess-11-2307-2011

Edgell HS (2006) Arabian deserts: nature, origin, and evolution. Springer, Berlin http://dx.doi.org/10.1007/1-4020-3970-0

Ehsan, MA, Tippett MK, Almazroui M, Ismail M, Yousef A, Kucharski F, Omar M, Hussein M, Alkhalaf AA (2017) Skill and predictability in multimodel ensemble forecasts for Northern Hemisphere regions with dominant winter precipitation. Clim Dyn 48:33093324. https://doi.org/10.1007/s00382-016-3267-4.

Eltahir EAB, Bras RL (1996) Precipitation recycling. Rev Geophys 34:367-378. https://doi.org/10.1029/96RG01927

Froidurot S, Diedhiou A (2017) Characteristics of wet and dry spells in the West African monsoon system. Atmos. Sci. Lett 18:125-131. https://doi.org/10.1002/asl.734

Funk C, Peterson P, Landsfeld M, Pedreros D, Verdin J, Shukla S, Husak G, Rowland J, Harrison L, Hoell A, Michaelsen J (2015) The climate hazards infrared precipitation with stations - a new environmental record for monitoring extremes. Scientific Data 2(1). https://doi.org/10.1038/sdata.2015.66

Gelaro R, Mccarty W, Suárez RT, Molod A, Takacs L, Randles CA, Darmenov A, Bosilovich MG, Reichle R, Wargan K, Coy L, Cullather R, Draper C, Akella S, Buchard V, Conaty A, Da Silva AM, Gu W, Kim GK, Koster R, Lucchesi R, Merkova D, Nielsen JE, Partyka G, Pawson S, Putman W, Rienecker M, Schubert SD, Sienkiewicz M, Zhao B, (2017) The Modern-Era Retrospective Analysis for Research and Applications, Version 2 (MERRA-2). J. Clim 30(14):5419-454. https://doi.org10.1175/jcli-d-16-0758.1.1

Gimeno L, Stohl A, Trigo RM, Dominguez F, Yoshimura K, Yu L, Drumond A, Durán-Quesada AM, Nieto R (2012) Oceanic and terrestrial sources of continental precipitation. Rev Geophys. 50:RG4003 https://doi.org/10.1029/2012RG000389 
Gimeno L, Vázquez M, Eiras-Barca J, Sorí R, Stojanovic M, Algarra I, Nieto R, Ramos AM, Durán-Quesada AM, Dominguez F (2020) Recent Progress on the Sources of Continental Precipitation as Revealed by Moisture Transport Analysis. Earth Science Reviews, 103070. https://doi.org/10.1016/j.earscirev.2019.103070

Gómez-Hernández M, Drumond A, Gimeno L, Garcia-Herrera R (2013) Variability of moisture sources in the Mediterranean region during the period 1980-2000: variability of Mediterranean moisture sources. Water Resour Res 49:6781-6794. https://doi.org/10.1002/wrcr.20538,

Harris I, Jones P, Osborn T, Lister D (2013) Updated high-resolution grids of monthly climatic observations - the CRU TS3.10 Dataset. International Journal of Climatology, 34(3):623642. https://doi.org/10.1002/joc.3711

Hersbach H, Bell B, Berrisford P, Hirahara S, Horányi A, Muñoz-Sabater J, Nicolas J, Peubey C, Radu R, Schepers D, Simmons A, Soci C, Abdalla S, Abellan X, Balsamo G, Bechtold P, Biavati G, Bidlot J, Bonavita M, De Chiara G, Dahlgren P, Dee D, Diamantakis M, Dragani R, Flemming J, Forbes R, Fuentes M, Geer A, Haimberger L, Healy S, Hogan RJ, Hólm E, Janisková M, Keeley S, Laloyaux P, Lopez P, Lupu C, Radnoti G, de Rosnay P, Rozum I, Vamborg F, Villaume S, Thépaut JN (2020) The era5 global reanalysis, Q. J. Royal Meteorol. Soc. , https://doi.org/10.1002/qj.3803

Kang IR, Kucharski F, Almazroui M, Abdulrahman KA (2015) Multidecadal Changes in the Relationship between ENSO and Wet-Season Precipitation in the Arabian Peninsula, J Clim 28(12):4743-4752, https://doi.org/10.1175/JCLI-D-14-00388.1,

Mbigi D, Xiao Z (2021) Tanzanian rainfall responses to El Niño and positive Indian Ocean Dipole events during 1951-2015. Atmospheric and Oceanic Science Letters, 10093, https://doi.org/10.1016/j.aosl.2021.100093

Mei R, Ashfaq M, Rastogi D, Leung LR, Dominguez F (2015) Dominating controls for Wetter South Asian Summer monsoon in the twenty-first century. J Clim 28:3400-3419. https://doi.org/10.1175/JCLI-D-14-00355

Nieto R, Gimeno L, Trigo RM (2006) A Lagrangian identification of major sources of Sahel moisture, Geophys Res Lett 33:L18707, https://doi.org/10.1029/2006GL027232

Saeed S, Almazroui M (2019) Impacts of mid-latitude circulation on winter precipitation over the Arabian Peninsula. Clim. Dyn. 53:5253-5264 https://doi.org/10.1007/s00382019-04862-6.

Schicker I, Radanovics S, Seibert P (2010) Origin and transport of Mediterranean moisture and air. Atmospheric Chemistry and Physics 10(11):5089-5105. https://doi.org/10.5194/acp10-5089-2010

Schneider U, Becker A, Finger P, Meyer-Christoffer A, Rudolf B, Ziese M (2011) GPCC Full Data Reanalysis Version 6.0 at $0.5^{\circ}$ : Monthly Land-Surface Precipitation from RainGauges built on GTS-based and Historic Data. https://doi.org/10.5676/DWD_GPCC/FD_M_V7_050

Sodemann H, Schwierz C, Wernli H (2008) Interannual variability of Greenland winter precipitation sources: Lagrangian moisture diagnostic and North Atlantic Oscillation influence, J Geophys Res 113:D03107, https://doi.org/10.1029/2007JD008503

Sorí R, Nieto R, Vicente-Serrano SM, Drumond A, Gimeno L (2017) A Lagrangian perspective of the hydrological cycle in the Congo River basin, Earth Syst Dynam 8:653-675, https://doi.org/10.5194/esd-8-653-2017 
Sorooshian S, Hsu K, Braithwaite D, Ashouri H, NOAA CDR Program (2014) NOAA Climate Data Record (CDR) of Precipitation Estimation from Remotely Sensed Information using Artificial Neural Networks (PERSIANN-CDR), Version 1 Revision 1. NOAA National Centers for Environmental Information. https://doi.org/10.7289/V51V5BWQ

Stohl A, James P (2005) A Lagrangian analysis of the atmospheric branch of the global water cycle. Part II: moisture transports between earth's ocean basins and river catchments. J. Hydrometeorol 6:961-984. https://doi.org/10.1175/JHM47 0.1

Spinks J, Lin YL (2014) Variability of the Subtropical Highs, African Easterly Jet and Easterly Wave Intensities over North Africa and Arabian Peninsula in Late Summer. Int J Climatol, 35(12):3540-3555 https://doi.org/10.1002/joc.4226

Trenberth KE (1999) Atmospheric moisture recycling: role of advection and local evaporation. J Clim 12:1368-1381. https://doi.org/10.1175/15200442(1999)012\%3c1368:AMRROA\%3e2.0.CO;2

Viste E, Sorteberg A (2013) Moisture transport into the Ethiopian highlands. Int J Climatol 33:249-263 https://doi.org/10.1002/joc.3409 


\section{Statements and Declarations}

$549 \quad$ Funding

550 This work is the supported by the U.S. Air Force Numerical Weather Modeling Program and

551 National Climate-Computing Research Center, which is located within the National Center for

552 Computational Sciences at the ORNL and supported under a Strategic Partnership Project, 2316-

553 T849-08, between DOE and NOAA. This research used resources of the Oak Ridge Leadership

554 Computing Facility, which is a DOE Office of Science User Facility supported under Contract

555 DE-AC05-00OR22725.

556

557

\section{Competing Interests}

558 The authors have no relevant financial or non-financial interests to disclose

559

560

\section{Author Contributions}

561 M.A. supervised the research. M.F.H collected data and performed analyses. All authors were

562 involved in discussions of the results. M.F.H prepared the manuscript with contributions from all

563 co-authors.

564 Data Availability

565 ERA5 data are available online (https://www.ecmwf.int/en/forecasts/datasets/reanalysis-

566 datasets/era5)

567 MERRA2 data are available online (https://gmao.gsfc.nasa.gov/reanalysis/MERRA-2/)

568 CRU data are available online

569 (https://catalogue.ceda.ac.uk/uuid/edf8febfdaad48abb2cbaf7d7e846a86)

570 GPCC data are available online (https://psl.noaa.gov/data/gridded/data.gpcc.html)

571 PERSIANN data are available online (https://www.ncei.noaa.gov/products/climate-data-

572 records/precipitation-persiann)

573 CHIRPS data are available online (https://www.chc.ucsb.edu/data/chirps)

574

575 


\section{Figure Captions}

577 Fig. 1 Evaporative source region and its sub-divisions. Region 1 represents the study area.

578 Fig. 2 Mean annual precipitation (mm) during 1980-2019 in a) CRU, b) PERSIANN, c) GPCC,

579 d) CHIRPS gridded observations and e) MERRA2, f) ERA5 reanalysis. Note that PERSIANN

580 data was unavailable for 2017 through 2019 and GPCC data was unavailable for 1980 through

5811982.

582 Fig. 3 Average recycling ratio (expressed in \% of the total) during the wet season (Nov-April).

583 a) Sum of all regions, b) Western Indian Ocean, c) Mediterranean and Caspian Sea, d) East

584 Africa, e) sum of North Atlantic and Europe, f) sum of North Africa and South Atlantic, g) sum

585 of the other regions. Results are based on the average of recycling ratio from ERA5 and

586 MERRA2.

587 Fig. 4 Climatological intra-seasonal variability in regional contributions, shown as 10-day

588 running mean area averaged over the Arabian Peninsula. Only those regions have been shown

589 that reach a seasonal maximum of more than 5\%. Note that symmetric averaging has been used

590 at the end points. Line colors match the ones used to define regions in Figure 1. Results are based

591 on the average of recycling ratio from ERA5 and MERRA2.

592 Fig. 5 (a) Regression of seasonal average winds and accumulated total sourced precipitation

593 anomalies onto the standardized ENSO index during the wet season. (b-e) same as in (a) but for

594 the seasonal accumulated sourced precipitation from individual source regions. The stippling

595 represents statistical significance at $90 \%$ confidence level. The two reanalysis are averaged

596 before regression.

597 Fig. 6 Same as in Figure 5 but for NAO. 
598 Fig. 7 Trends (mm/year) in seasonal accumulated contribution from each source region over 599 1980-2019. Stippling indicates significance at 95\% confidence level. Trends are based on the 600 average of ERA5 and MERRA2.

601 Fig. S1 Climatological percent of annual precipitation received during the wet season (1980-

602 2019) in a) CRU, b) PERSIANN, c) GPCC, d) CHIRPS gridded observations and e) MERRA2,

603 f) ERA5 reanalysis. Note that PERSIANN data was unavailable for 2017 through 2019 and

604 GPCC data was unavailable for 1980 through 1982.

605 Fig. S2 Average recycling ratio (expressed in \% of the total) during the wet season (Nov-April)

606 from individual source regions. Results are based on the average of recycling ratios from ERA5 607 and MERRA2.

608 Fig. S3 Average recycling ratio (expressed in \% of the total) during the wet season (Nov-April) 609 from individual source regions in ERA5.

610 Fig. S4 Average recycling ratio (expressed in \% of the total) during the wet season (Nov-April) 611 from individual source regions in MERRA2.

612 Fig. S5 Mean monthly precipitation (mm) during 1980-2019 in a) CRU, b) PERSIANN, c)

613 GPCC, d) CHIRPS gridded observations and e) MERRA2, f) ERA5 reanalysis. Note that

614 PERSIANN data was unavailable for 2017 through 2019 and GPCC data was unavailable for 6151980 through 1982.

616 Fig. S6 Regression of anomalies in seasonal accumulated sourced precipitation from individual 617 regions onto the standardized ENSO index during the wet season. The stippling represents 618 statistical significance at 90\% confidence level. Results are based on the average of ERA5 and 619 MERRA2. 
620 Fig. S7 Regression of anomalies in seasonal accumulated sourced precipitation from individual

621 regions onto the standardized NAO index during the wet season. The stippling represents

622 statistical significance at 90\% confidence level. Results are based on the average of ERA5 and

623 MERRA2.

624 Fig. S8 (a) Regression of Nov-Dec average winds and accumulated total sourced precipitation

625 anomalies onto the standardized ENSO index. (b-e) same as in (a) but for the seasonal

626 accumulated sourced precipitation from individual source regions. The stippling represents

627 statistical significance at $90 \%$ confidence level. Results are based on the average of ERA5 and

628 MERRA2.

629 Fig. S9 Same as in Figure S8 but for Jan-Feb.

630 Fig. S10 Same as in Figure S8 but for Mar-Apr.

631 Fig. S11 (a) Regression of Nov-Dec average winds and accumulated total sourced precipitation

632 anomalies onto the standardized NAO index. (b-e) same as in (a) but for the seasonal

633 accumulated sourced precipitation from individual source regions. The stippling represents

634 statistical significance at 90\% confidence level. Results are based on the average of ERA5 and

635 MERRA2.

636 Fig. S12 Same as in Figure S11 but for Jan-Feb.

637 Fig. S13 Same as in Figure S11 but for Mar-Apr.

638 Fig. S14 Seasonal accumulated precipitation trends (mm/year) during 1980-2019 in a) CRU, b)

639 PERSIANN, c) GPCC, d) CHIRPS gridded observations and e) MERRA2, f) ERA5 reanalysis.

640 Note that PERSIANN data was unavailable for 2017 through 2019 and GPCC data was

641 unavailable for 1980 through 1982. The stippling represents statistical significance at $95 \%$

642 confidence level. 
643 Fig. S15 Same as in Figure S14 but for the whole evaporative source region.

644 Fig. S16 Trends (mm/year) in seasonal accumulated contribution from each source region over 645 1980-2019 in ERA5. Stippling indicates significance at 95\% confidence level.

646 Fig. S17 Trends (mm/year) in seasonal accumulated contribution from each source region over 647 1980-2019 in MERRA2. Stippling indicates significance at 95\% confidence level. 


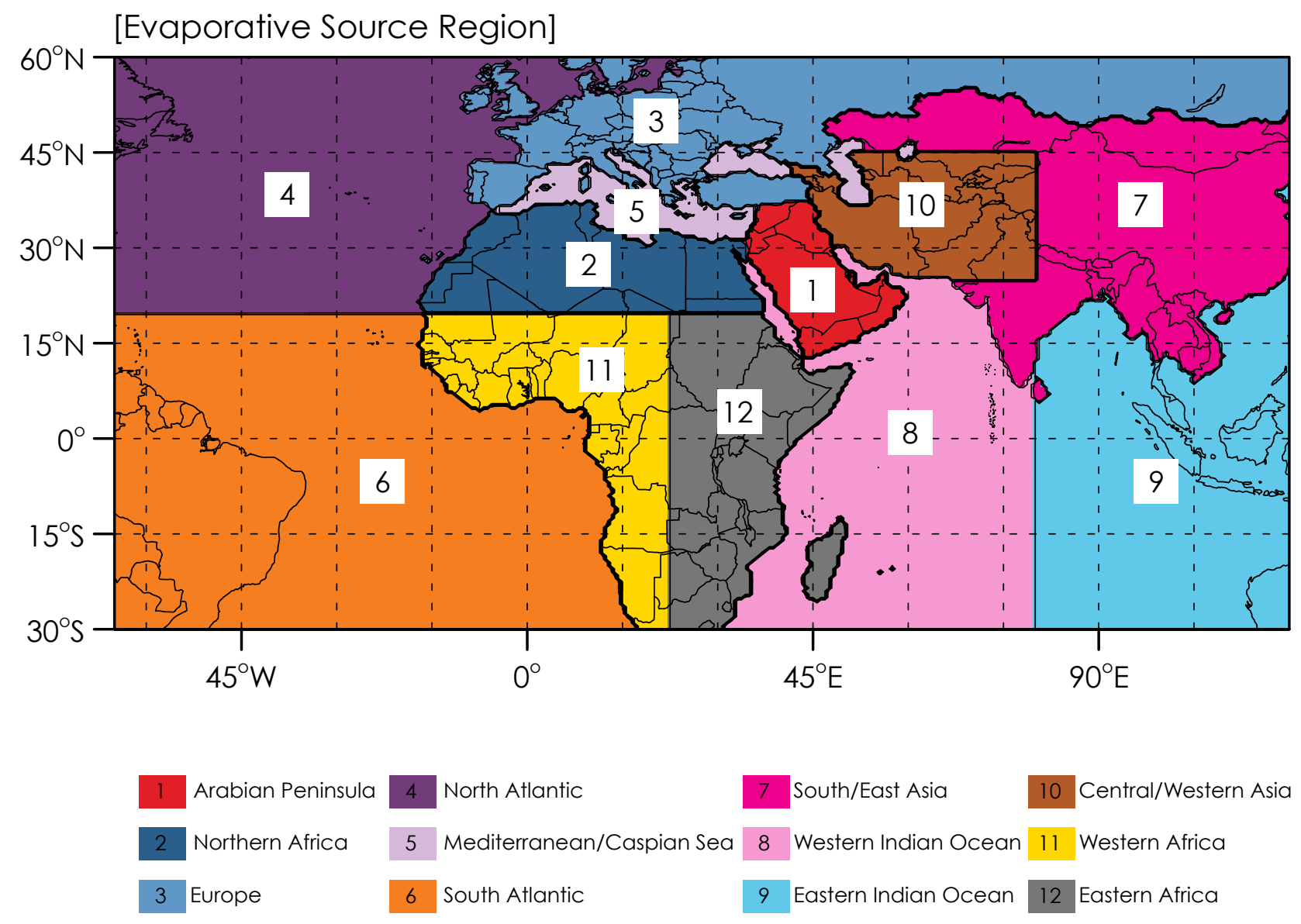

Figure 1. Evaporative source region and its sub-divisions. Region 1 represents the study area. 


\section{[Annual Precipitation]}
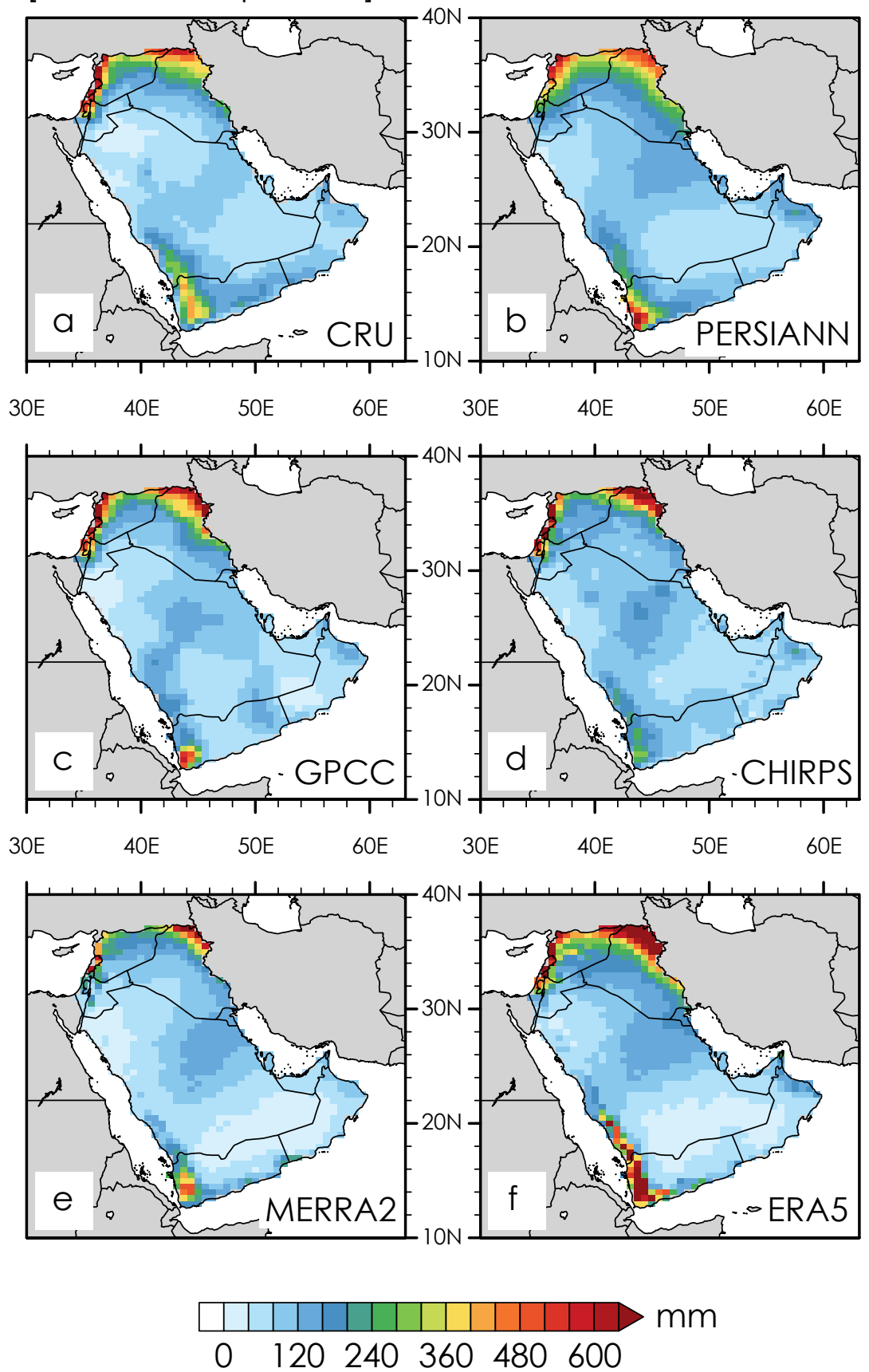

Figure 2. Accumulated mean annual precipitation ( $\mathrm{mm}$ ) during 1980-2019 in a) CRU, b) PERSIANN, c) GPCC, d) CHIRPS gridded observations and e) MERRA2, f) ERA5 reanalysis. Note that PERSIANN data was unavailable for 2017 through 2019 and GPCC data was unavailable for 1980 through 1982. 
[Recycling Ratio]
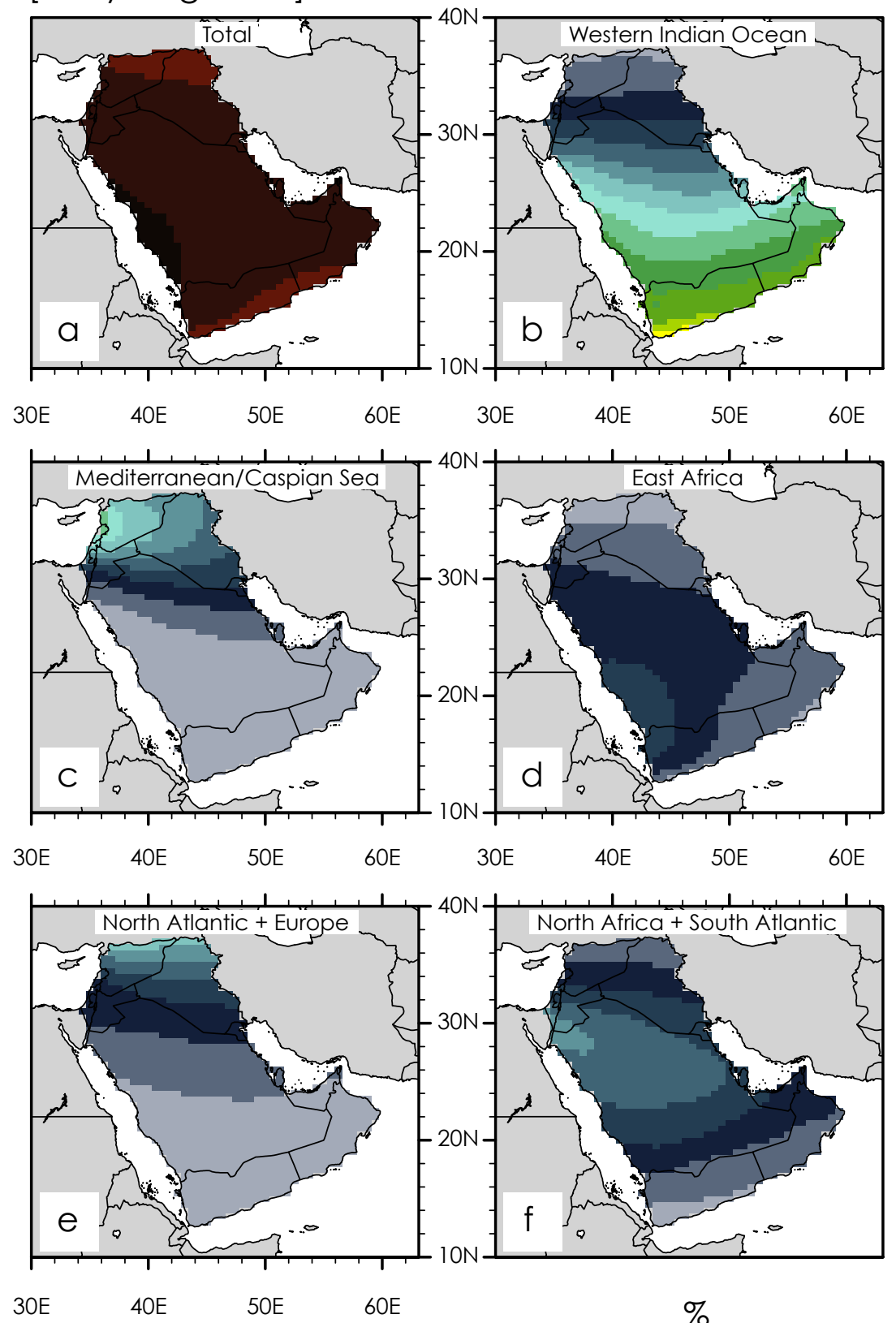

$\%$

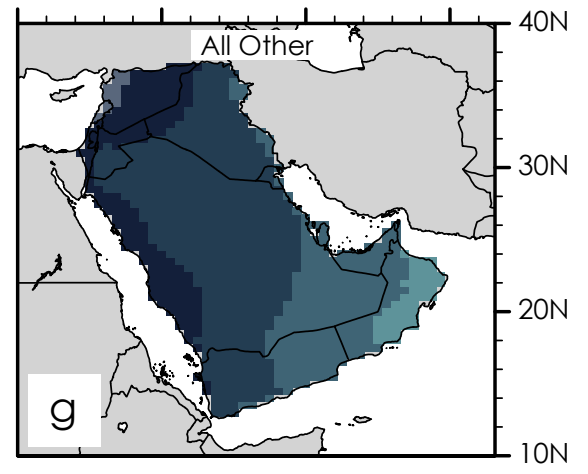

$\begin{array}{llllll}0 & 20 & 40 & 60 & 80 & 100\end{array}$

Figure 3. Average recycling ratio (expressed in \% of the total) during the wet season (Nov-April). a) Sum of all regions, b) Western Indian Ocean, c) Mediterranean and Caspian Sea, d) East Africa, e) sum of North Atlantic and Europe, f) sum of North Africa and South Atlantic, g) sum of the other regions. Results are based on the average of recycling ratio from ERA5 and MERRA2. 


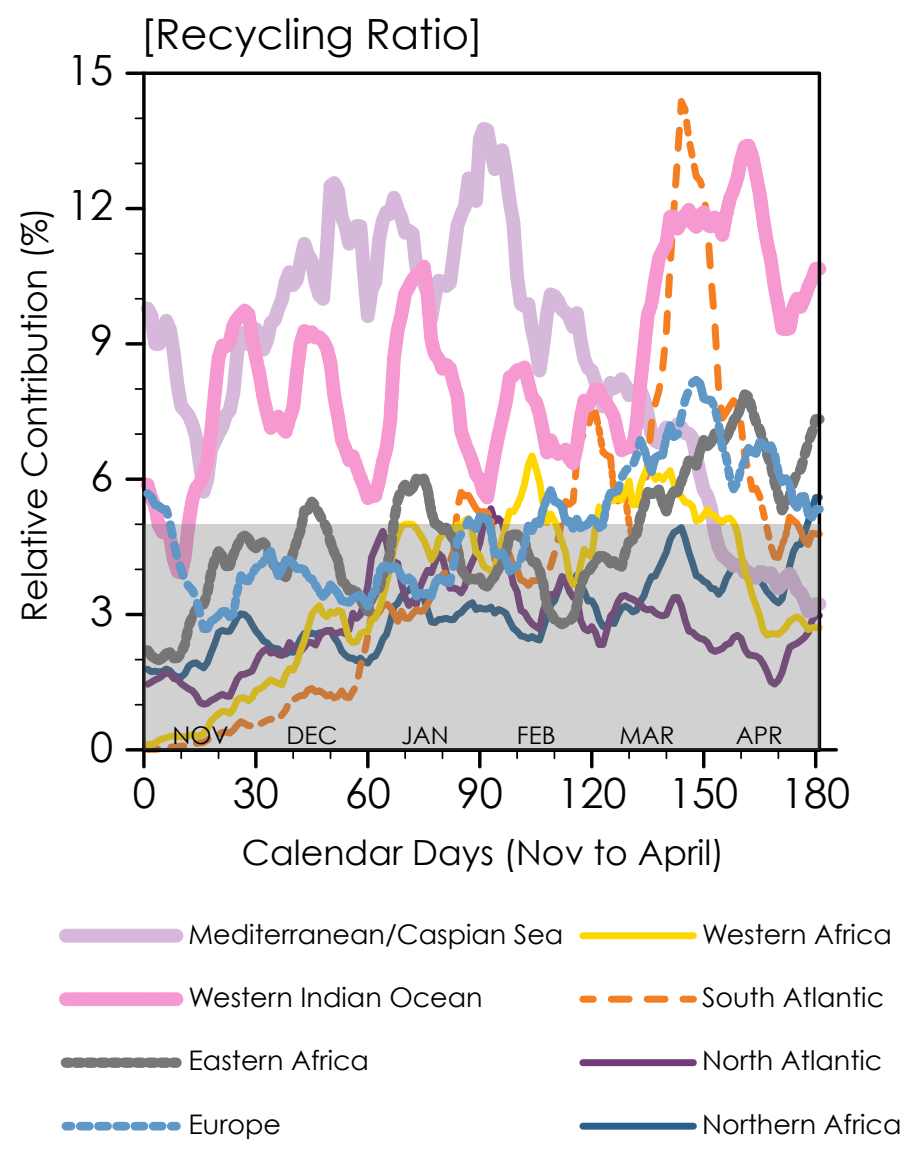

Figure 4. Climatological intra-seasonal variability in regional contributions, shown as 10-day running mean area averaged over the Arabian Peninsula. Only those regions have been shown that reach a seasonal maximum of more than $5 \%$. Note that symmetric averaging has been used at the end points. Line colors match the ones used to define regions in Figure 1. Results are based on the average of recycling ratio from ERA5 and MERRA2. 


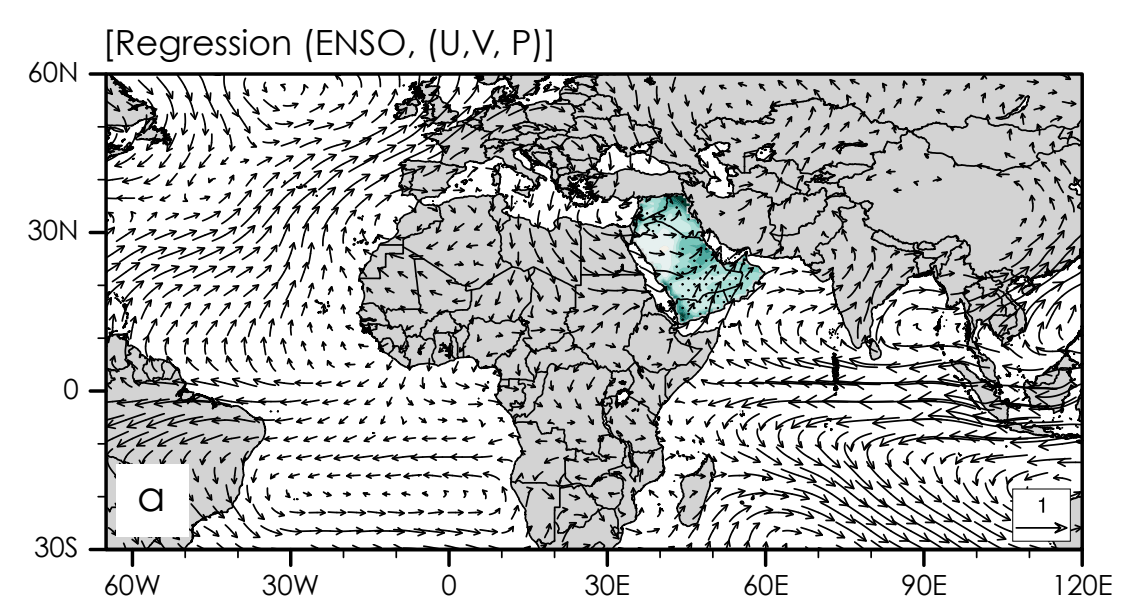

[Regression (ENSO, P)]
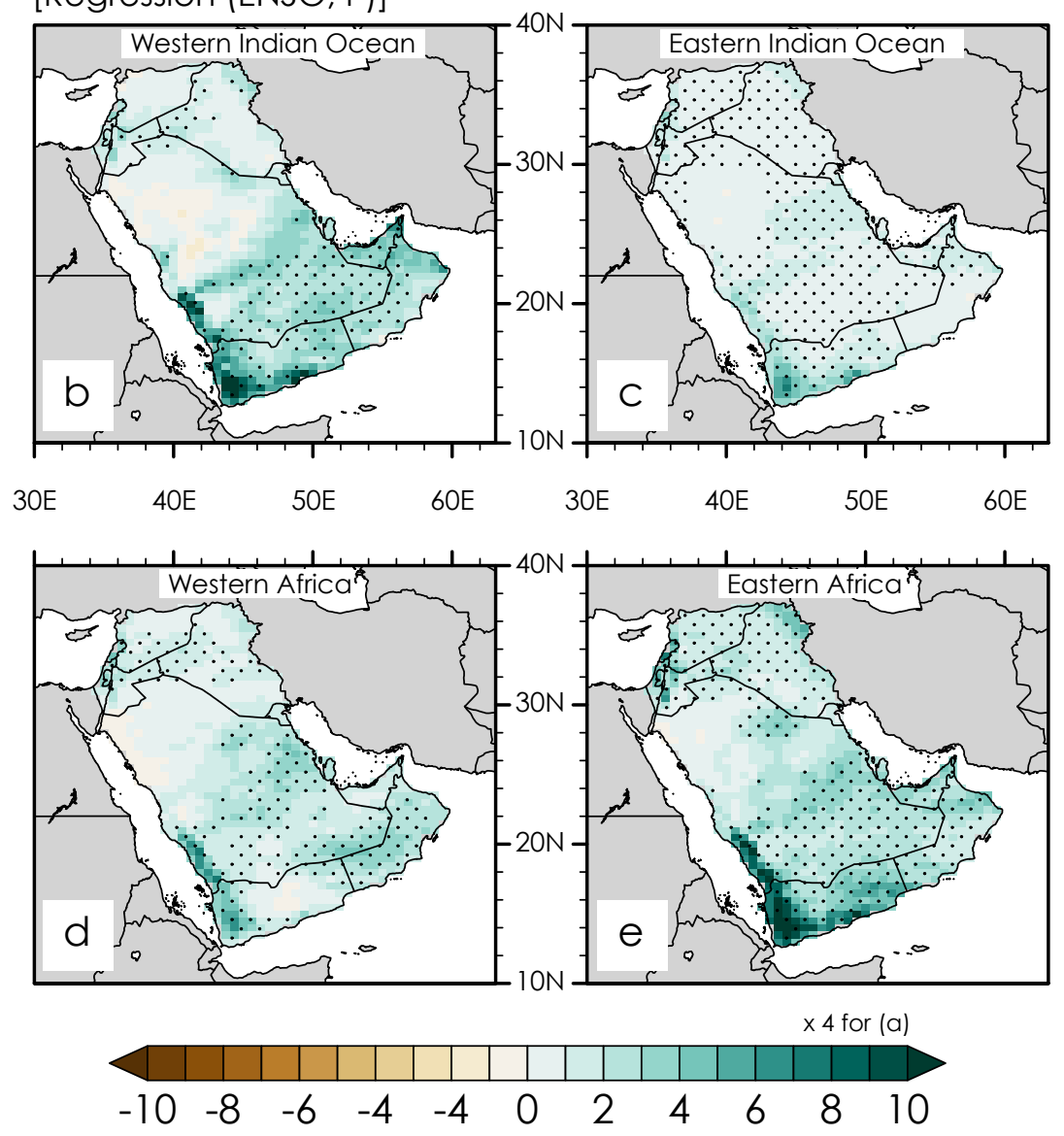

Figure 5. (a) Regression of seasonal average winds and accumulated total sourced precipitation anomalies onto the standardized ENSO index during the wet season. (b-e) same as in (a) but for the seasonal accumulated sourced precipitation from individual source regions. The stippling represents statistical significance at $90 \%$ confidence level. The two reanalysis are averaged before regression. 


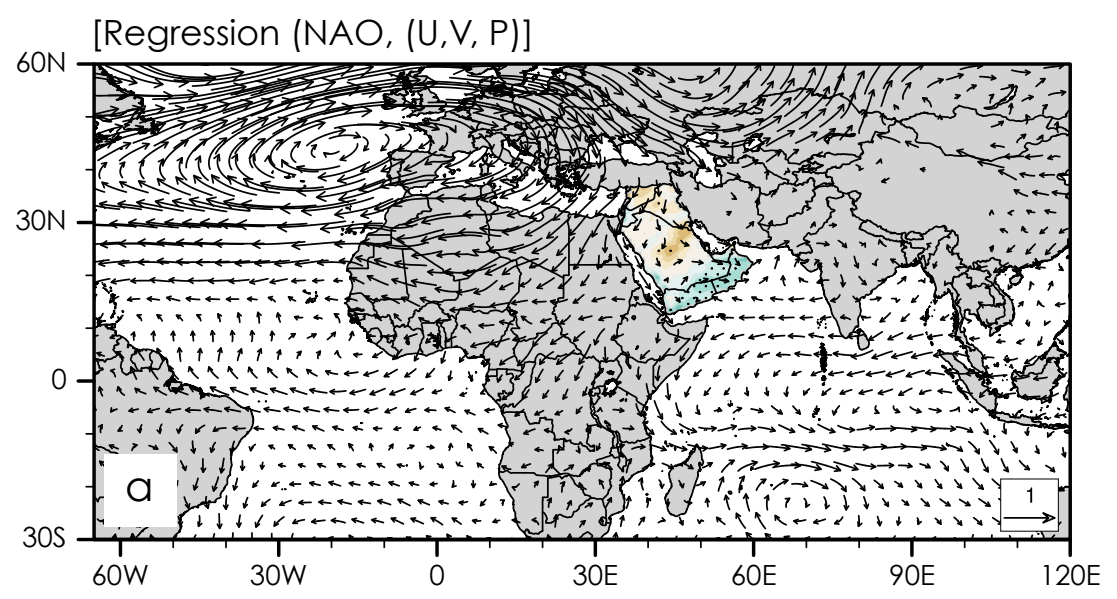

[Regression (NAO, P)]
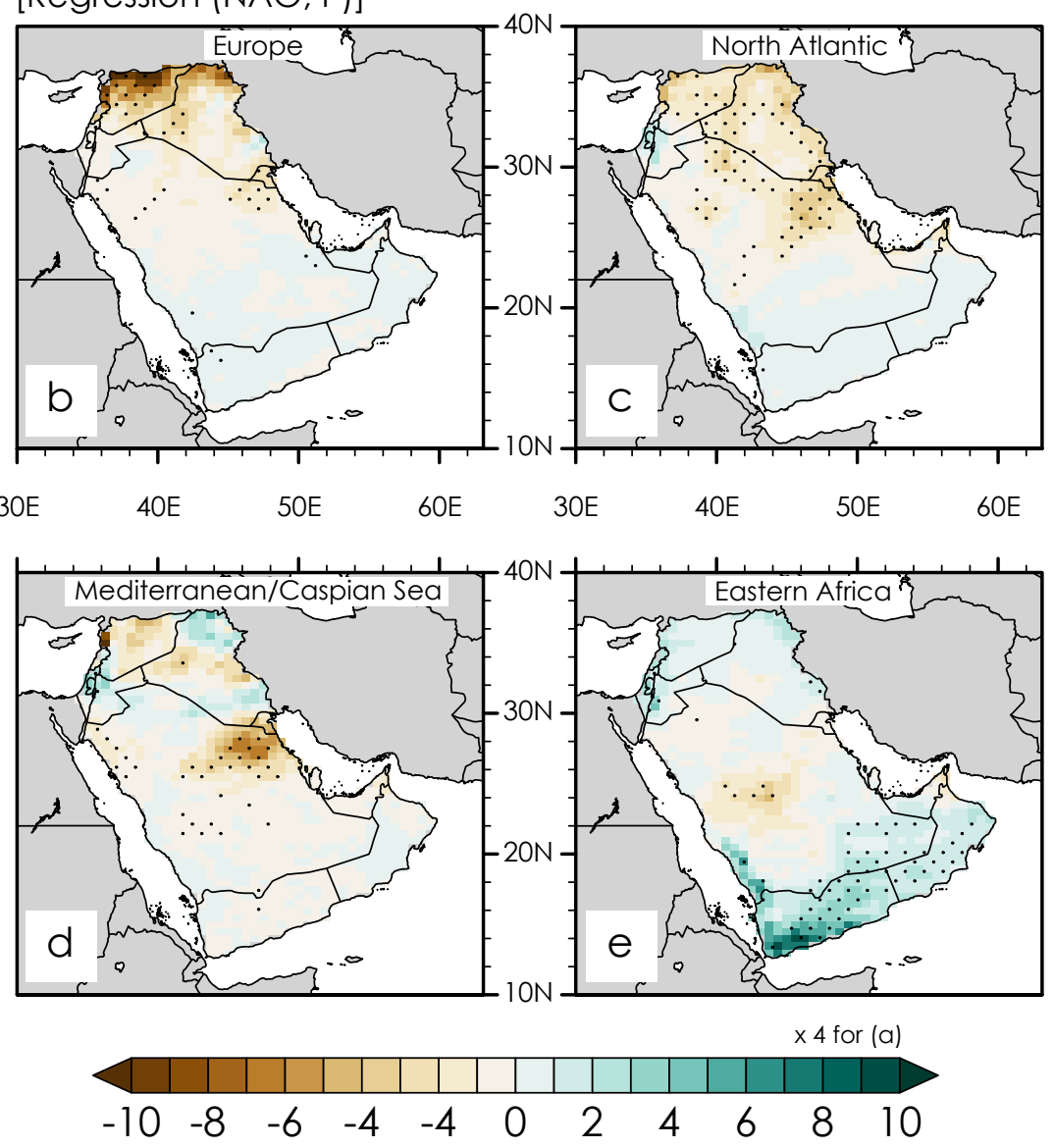

Figure 6. Same as in Figure 5 but for the NAO index. 
[Trends in Seasonal Contribution]
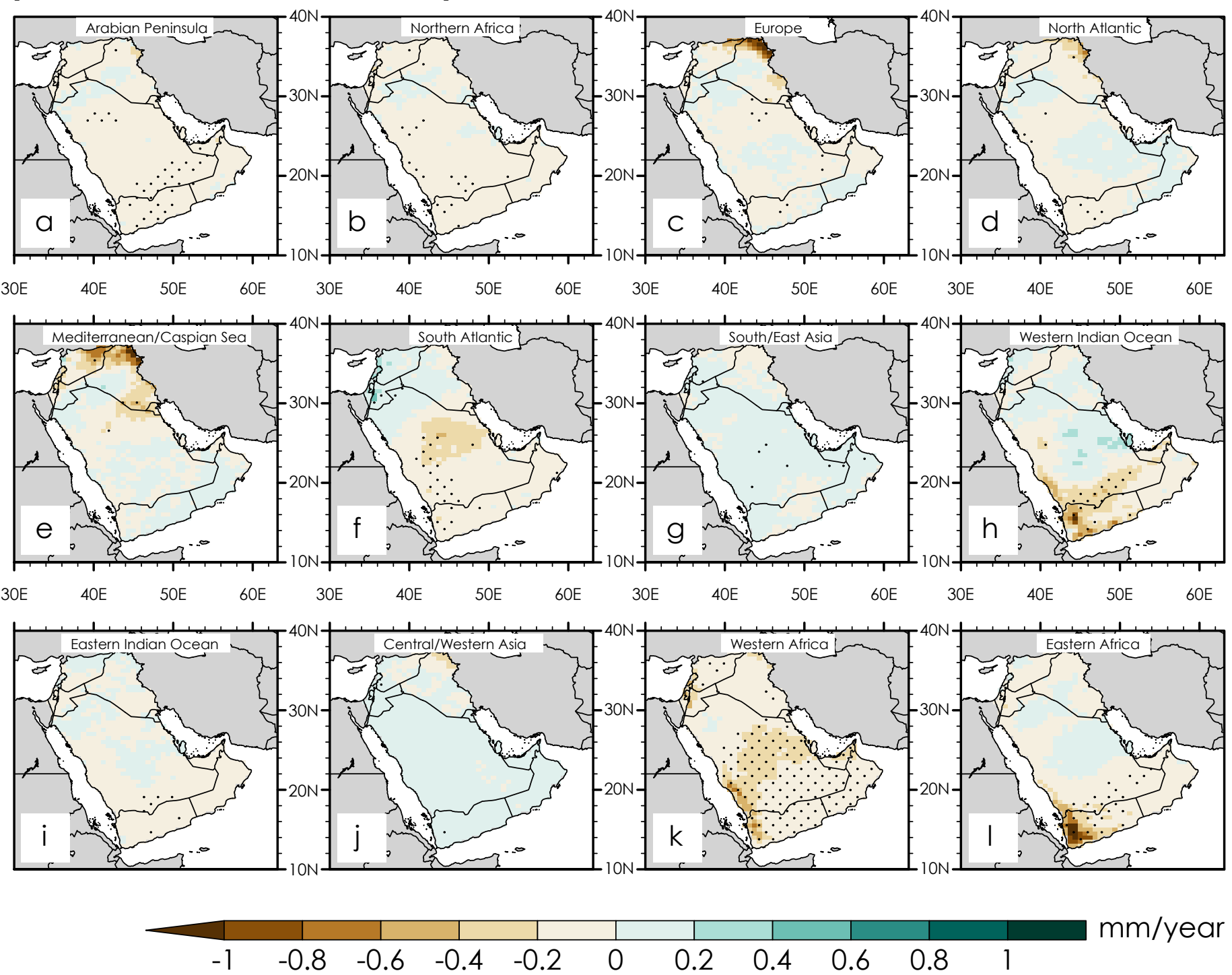

Figure 7. Trends ( $\mathrm{mm} /$ year) in seasonal contribution from each source region over 1980-2019. Stippling indicates significance at $95 \%$ confidence level. Trends are based on the average of ERA5 and MERRA2. 
[Wet Season Precipitation]
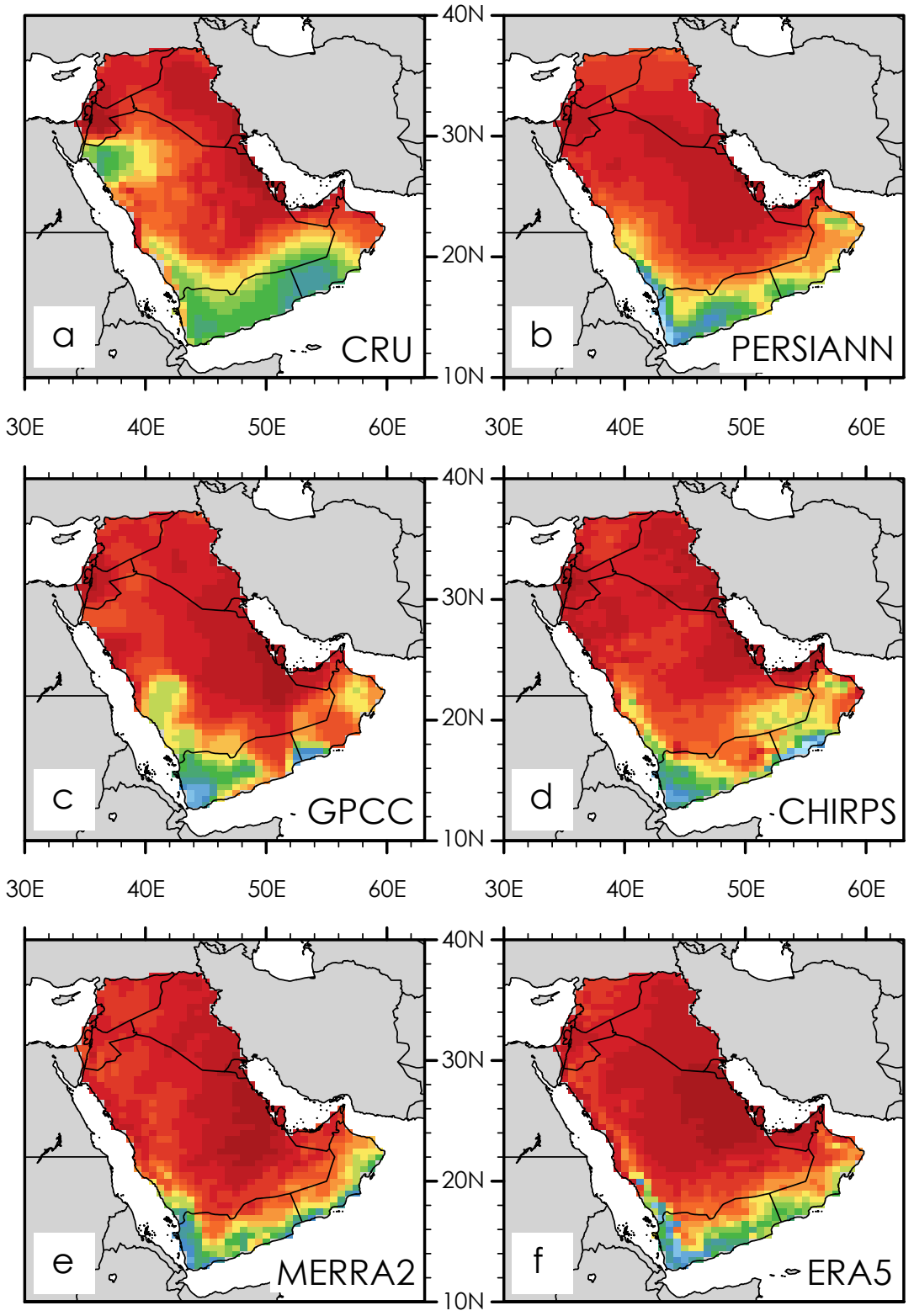

\% of annual

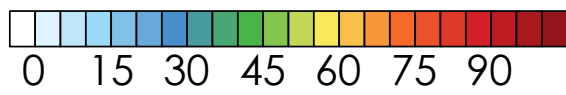

Figure S1. Climatological percent of annual precipitation received during the wet season (1980-2019) in a) CRU, b) PERSIANN, c) GPCC, d) CHIRPS gridded observations and e) MERRA2, f) ERA5 reanalysis. Note that PERSIANN data was unavailable for 2017 through 2019 and GPCC data was unavailable for 1980 through 1982. 


\section{[Recycling Ratio]}
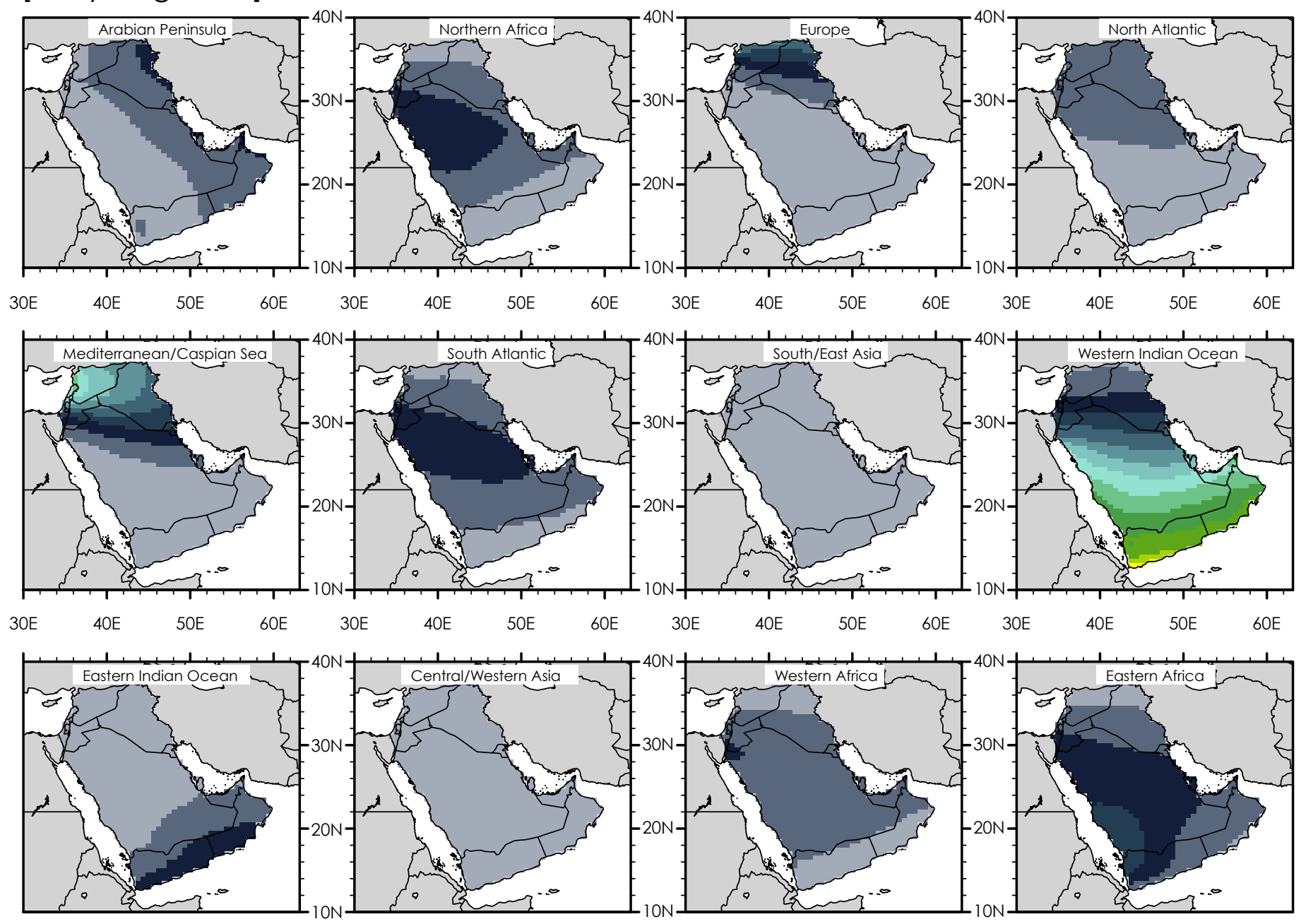

fractional contribution in percent

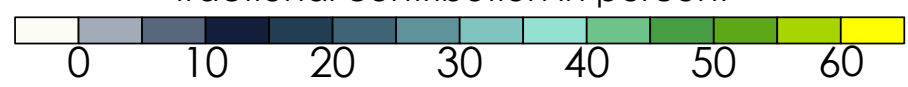

Figure S2. Average recycling ratio (expressed in \% of the total) during the wet season (Nov-April) from individual source regions. Results are based on the average of recycling ratios from ERA5 and MERRA2. 

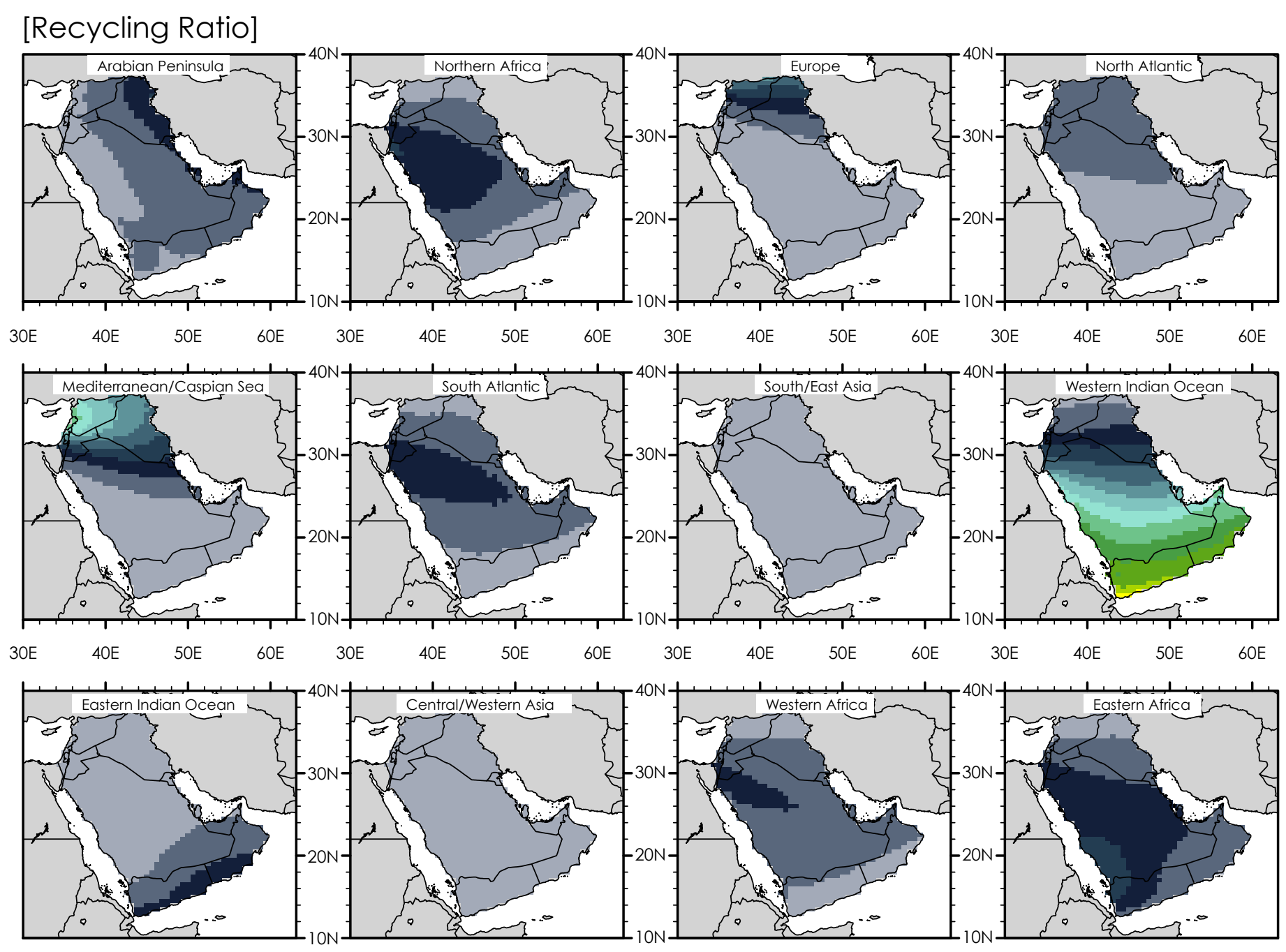

fractional contribution in percent

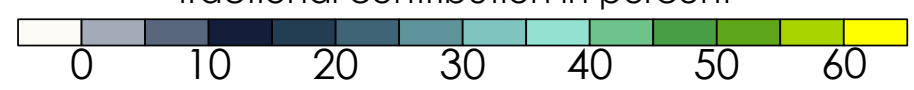

Figure S3. Average recycling ratio (expressed in \% of the total) during the wet season (Nov-April) from individual source regions in ERA5. 
[Recycling Ratio]
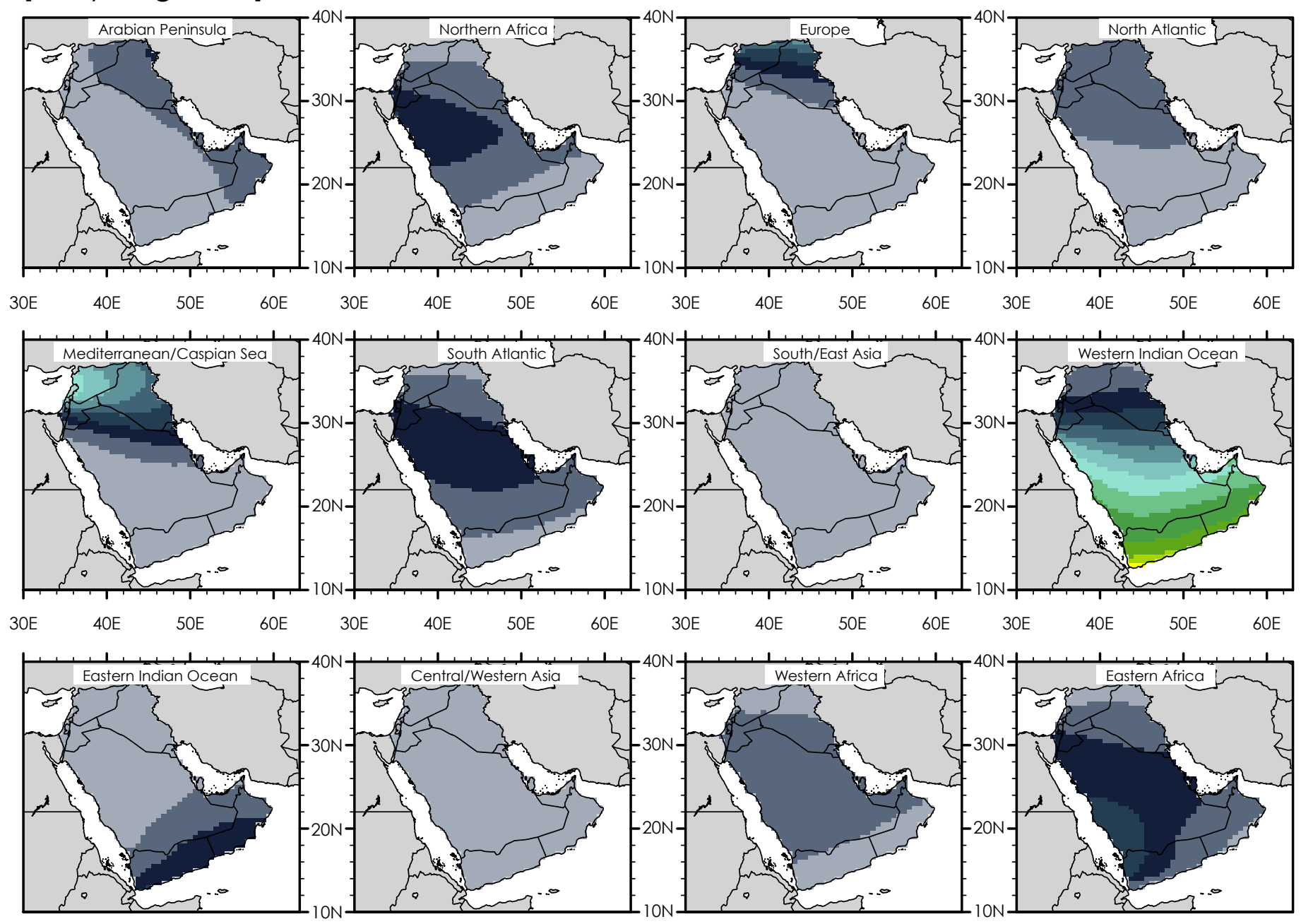

fractional contribution in percent

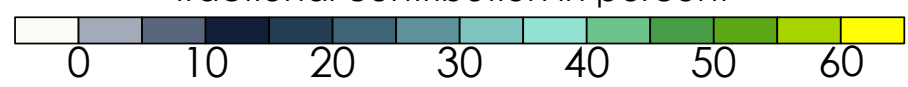

Figure S4. Average recycling ratio (expressed in \% of the total) during the wet season (Nov-April) from individual source regions in MERRA2. 

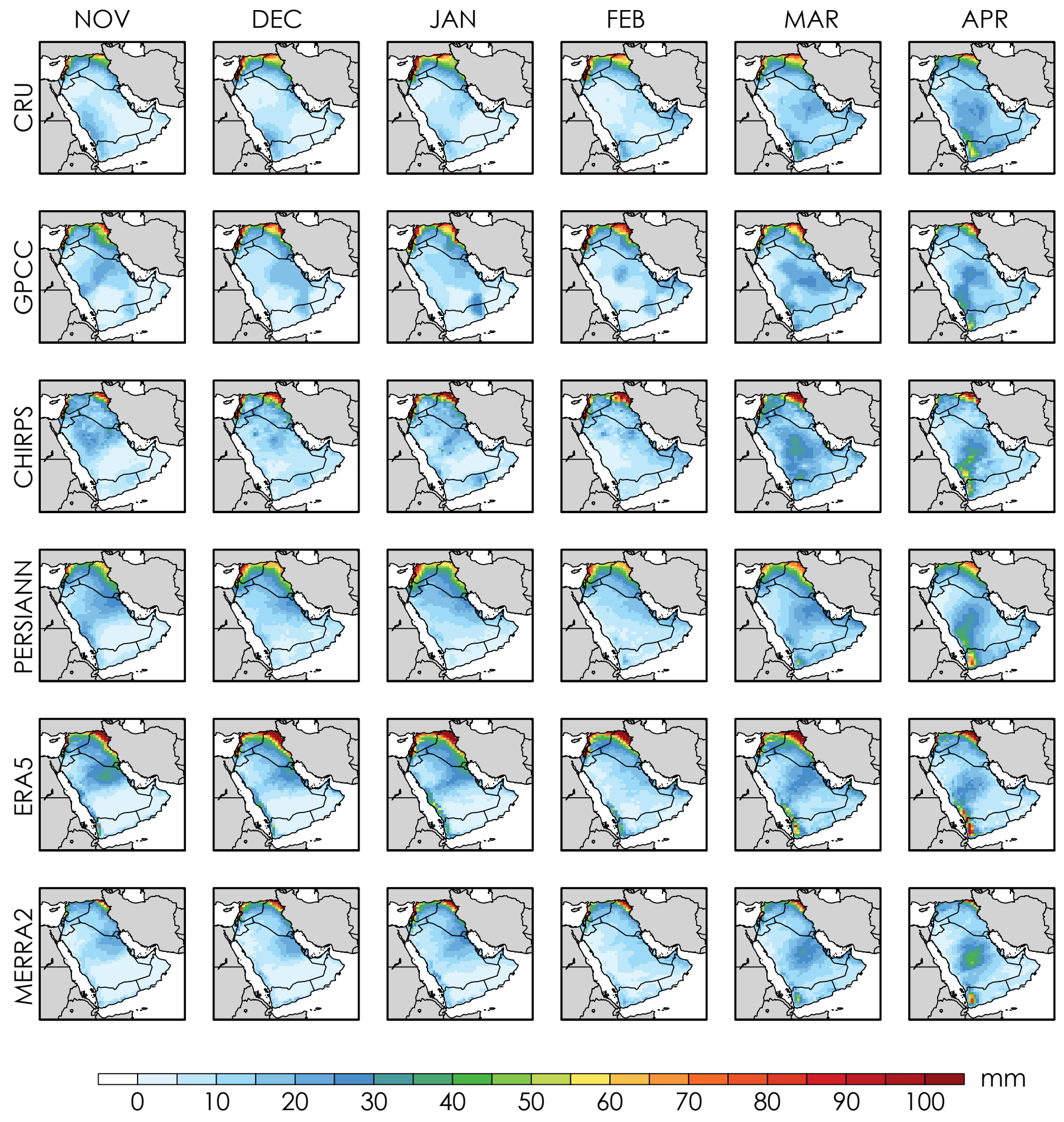

Figure 5. Accumulated mean monthly precipitation $(\mathrm{mm})$ during 1980-2019 in (1st row) CRU, (2nd row) PERSIANN, (3rd row) GPCC, (4th row) CHIRPS gridded observations and (5th row) MERRA2, (6th row) ERA5 reanalysis. Note that PERSIANN data was unavailable for 2017 through 2019 and GPCC data was unavailable for 1980 through 
[Regression (ENSO, P]
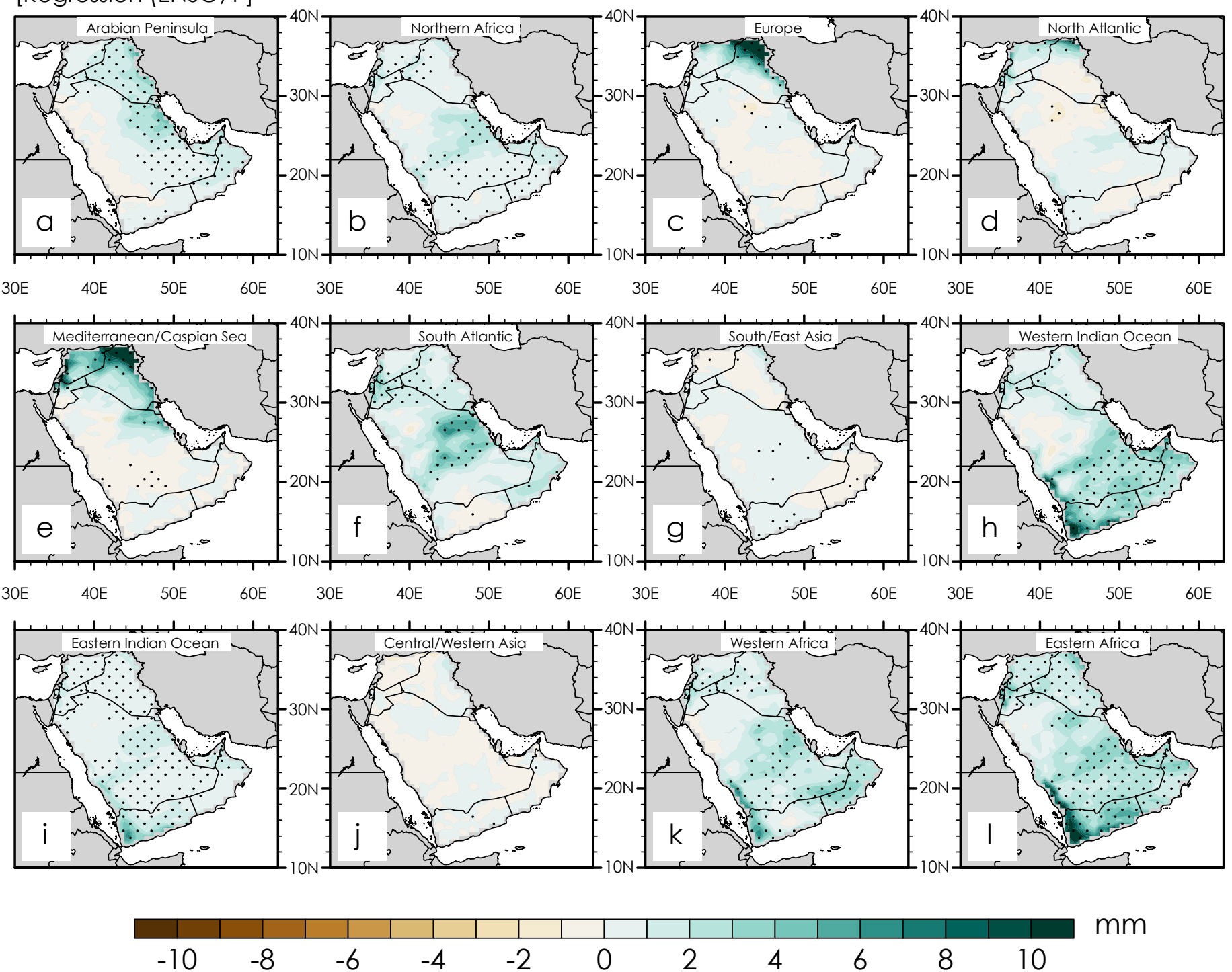

Figure S6. Regression of anomalies in seasonal accumulated sourced precipitation from individual regions onto the standardized ENSO index during the wet season. The stippling represents statistical significance at $90 \%$ confidence level. The two reanalysis are averaged before regression. 
[Regression (NAO, P]
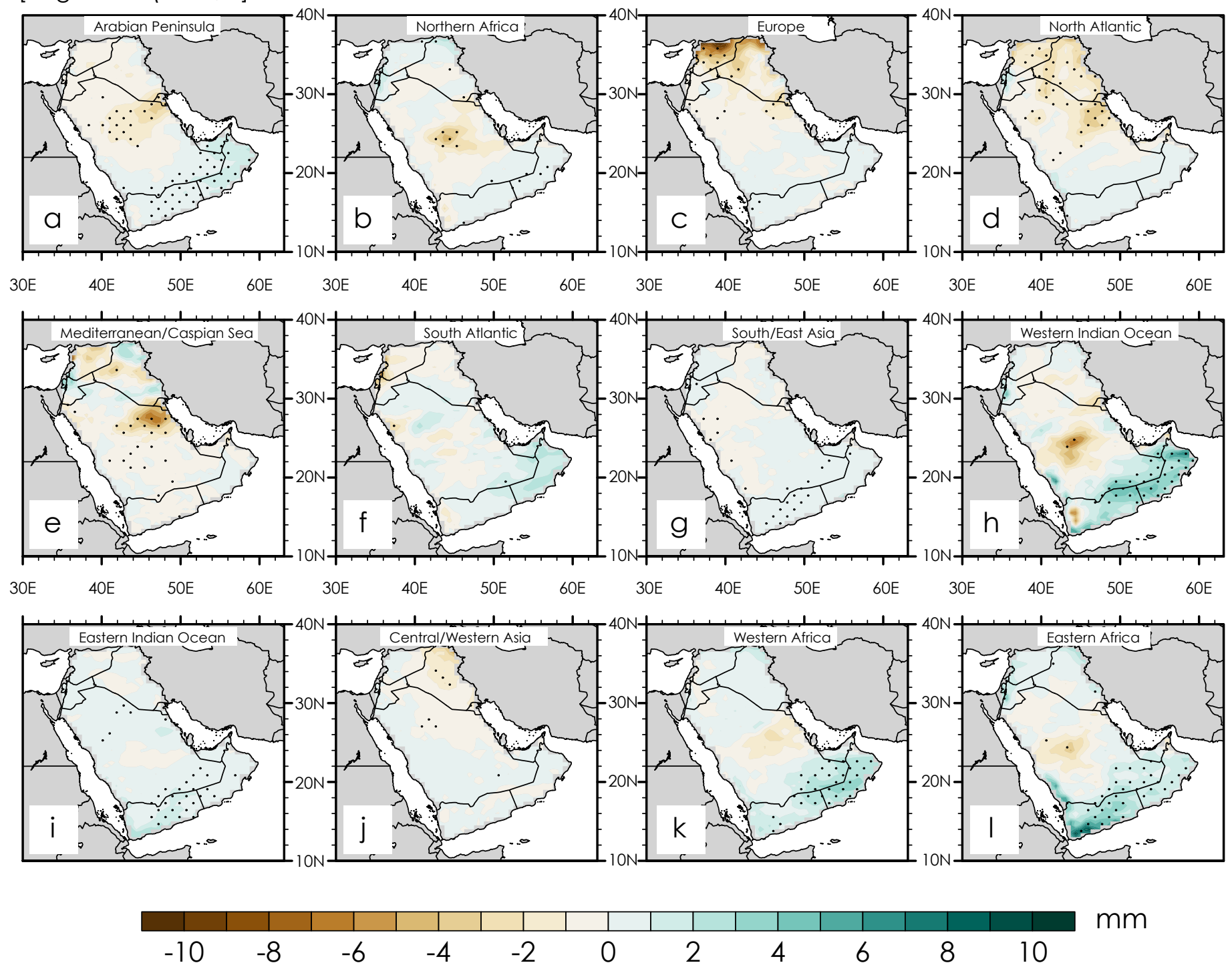

Figure S7. Regression of anomalies in seasonal accumulated sourced precipitation from individual regions onto the standardized NAO index during the wet season. The stippling represents statistical significance at $90 \%$ confidence level. The two reanalysis are averaged before regression. 


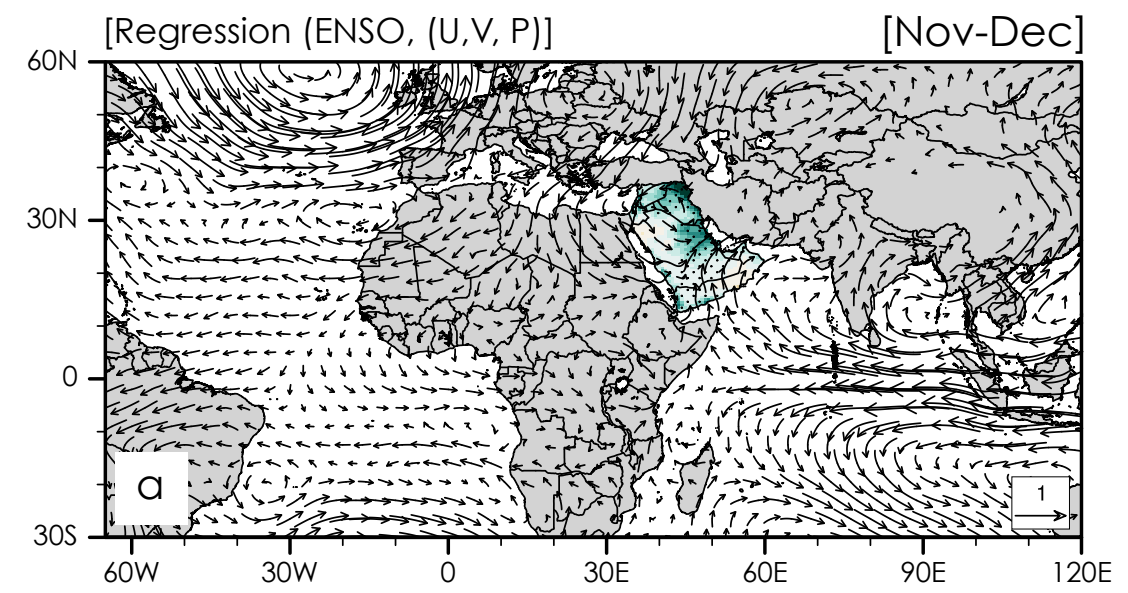

[Regression (ENSO, P]
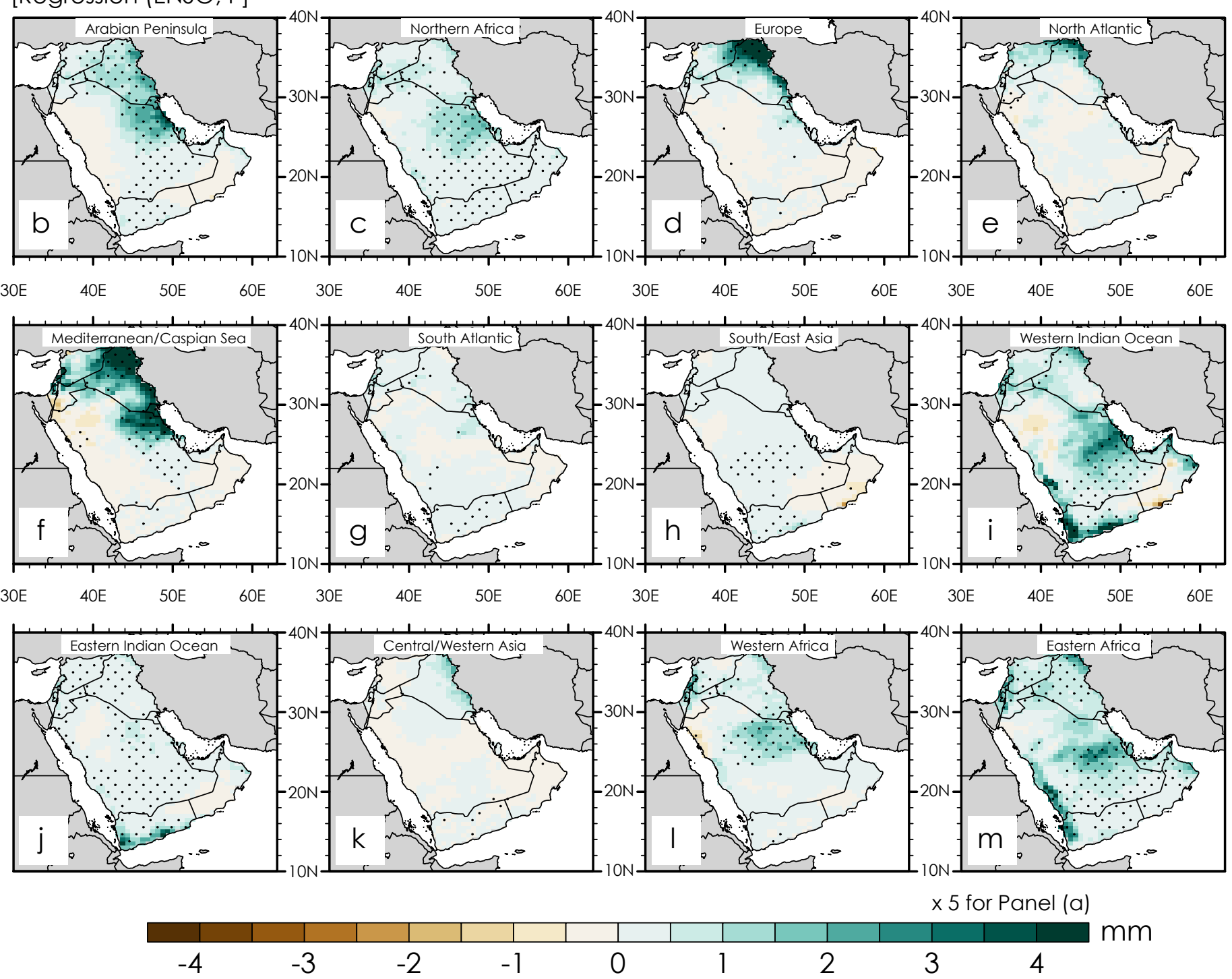

Figure S8. (a) Regression of Nov-Dec average winds and accumulated total sourced precipitation anomalies onto the standardized ENSO index. (b-e) same as in (a) but for the seasonal accumulated sourced precipitation from individual source regions. The stippling represents statistical significance at $90 \%$ confidence level. The two reanalysis are averaged before regression. 


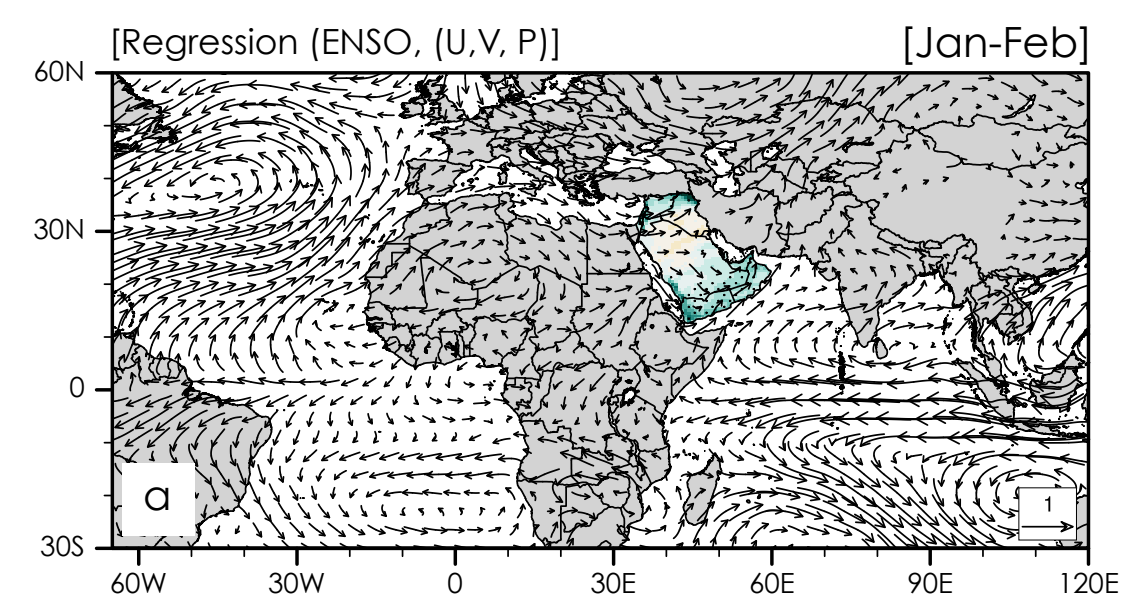

[Regression (ENSO, P]
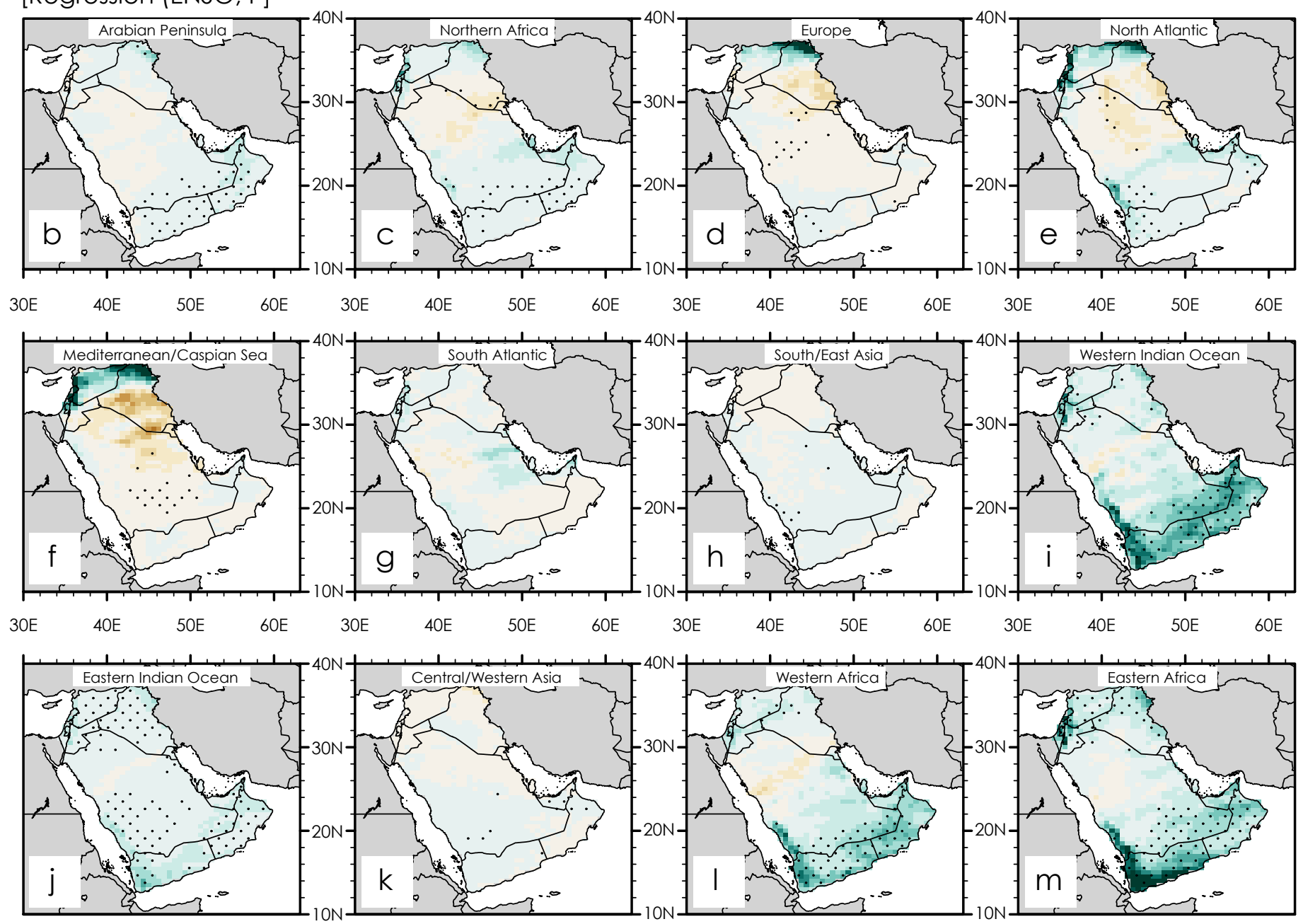

$x 5$ for Panel (a)

\begin{tabular}{|l|l|l|l|l|l|l|l|l|l|l|l|l|l|}
\hline & & & & & & & & & & & & & \\
-4 & -3 & -2 & -1 & 0 & 1 & 2 & 3 & 4
\end{tabular}

Figure S9. Same as in Figure S8 but for Jan-Feb. 


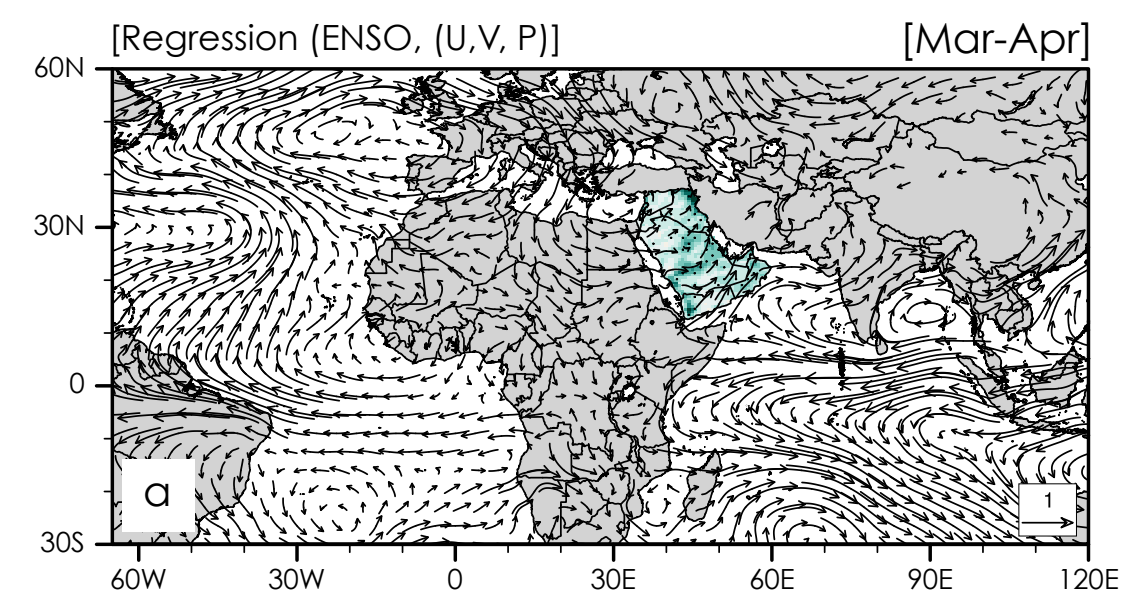

[Regression (ENSO, P]
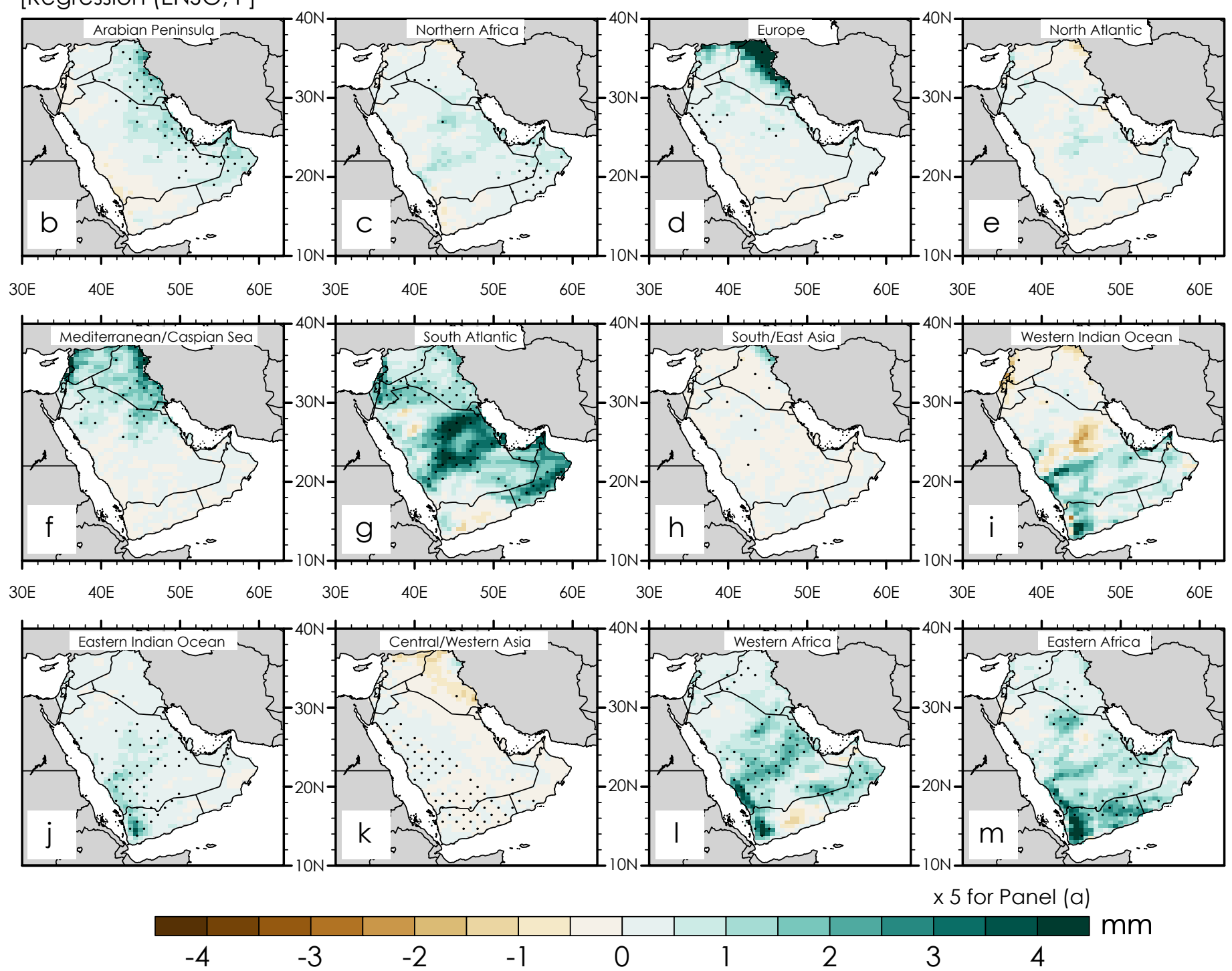

Figure S10. Same as in Figure S8 but for Mar-Apr. 


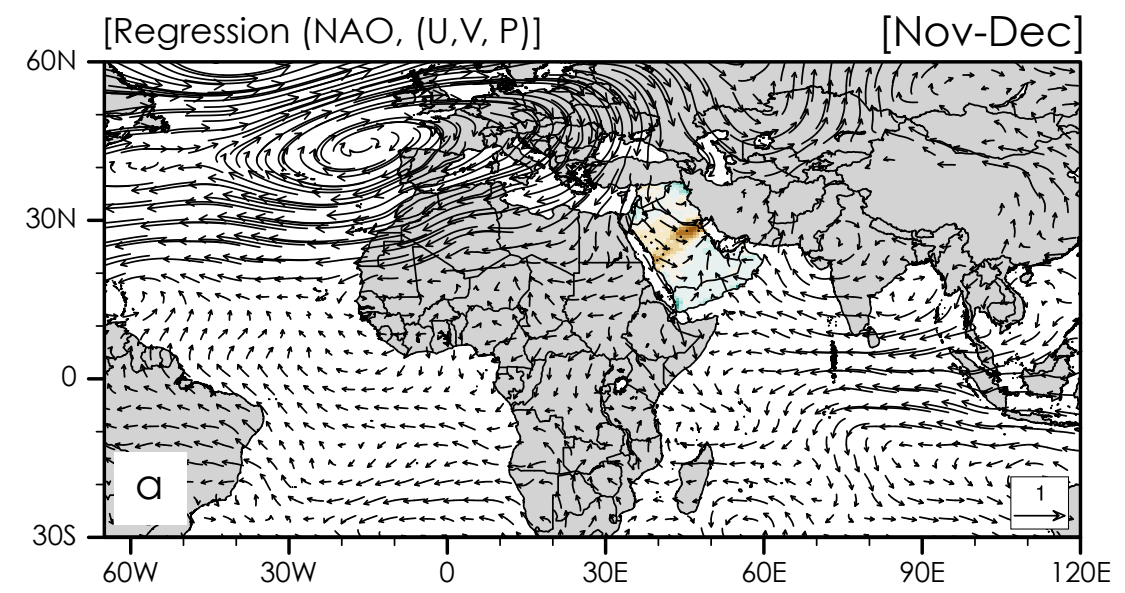

[Regression (NAO, P]
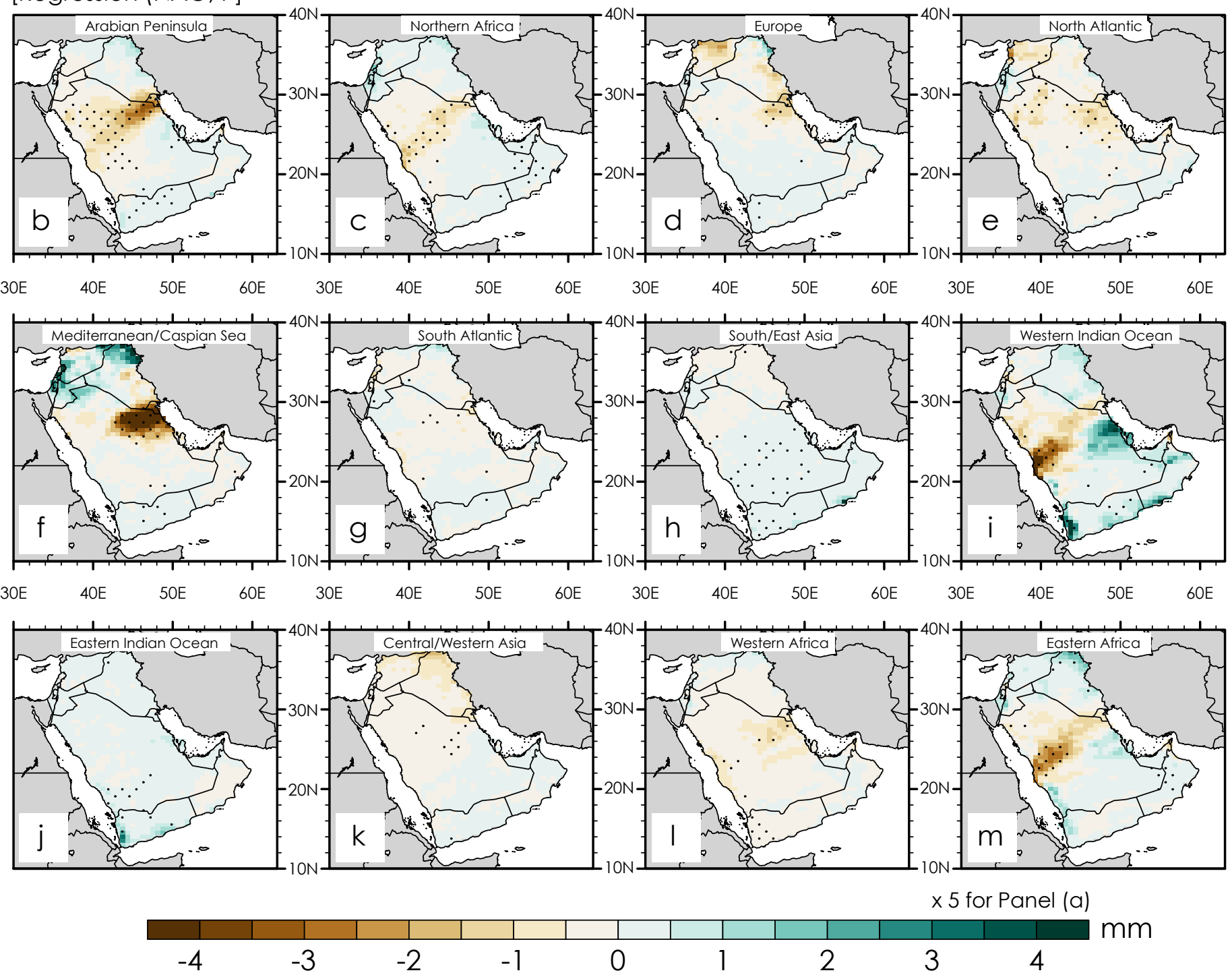

Figure S11. (a) Regression of Nov-Dec average winds and accumulated total sourced precipitation anomalies onto the standardized NAO index. (b-e) same as in (a) but for the seasonal accumulated sourced precipitation from individual source regions. The stippling represents statistical significance at $90 \%$ confidence level. The two reanalysis are averaged before regression. 


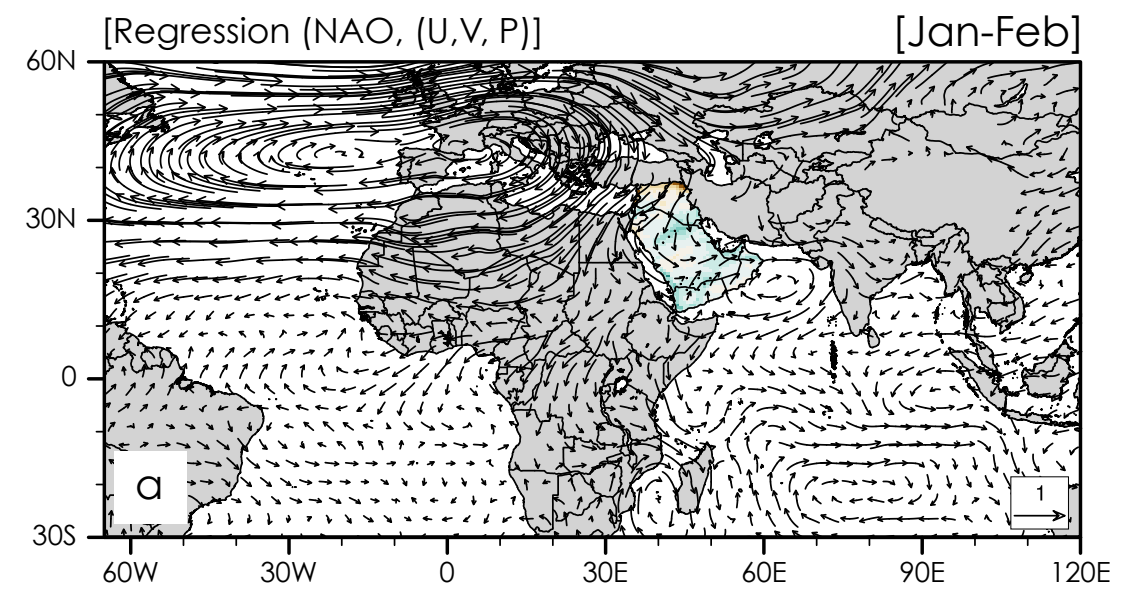

[Regression (NAO, P]
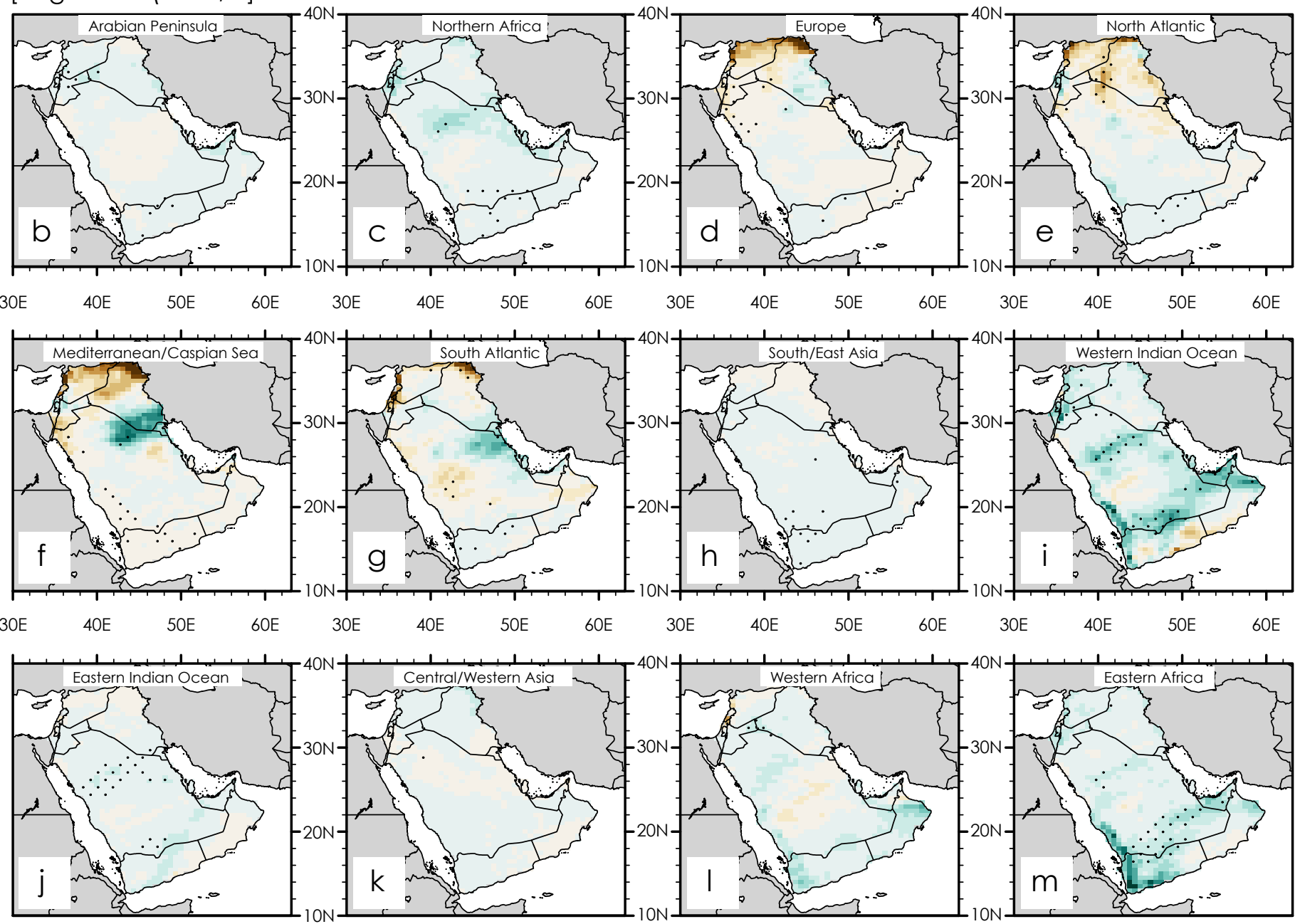

$x 5$ for Panel (a)

\begin{tabular}{|l|l|l|l|l|l|l|l|l|l|l|l|l|l|}
\hline & & & & & & & & & & & & & \\
\hline-4 & -3 & -2 & -1 & 0 & 1 & 2 & 3 & 4
\end{tabular}

Figure S12. Same as in Figure S1 1 but for Jan-Feb. 


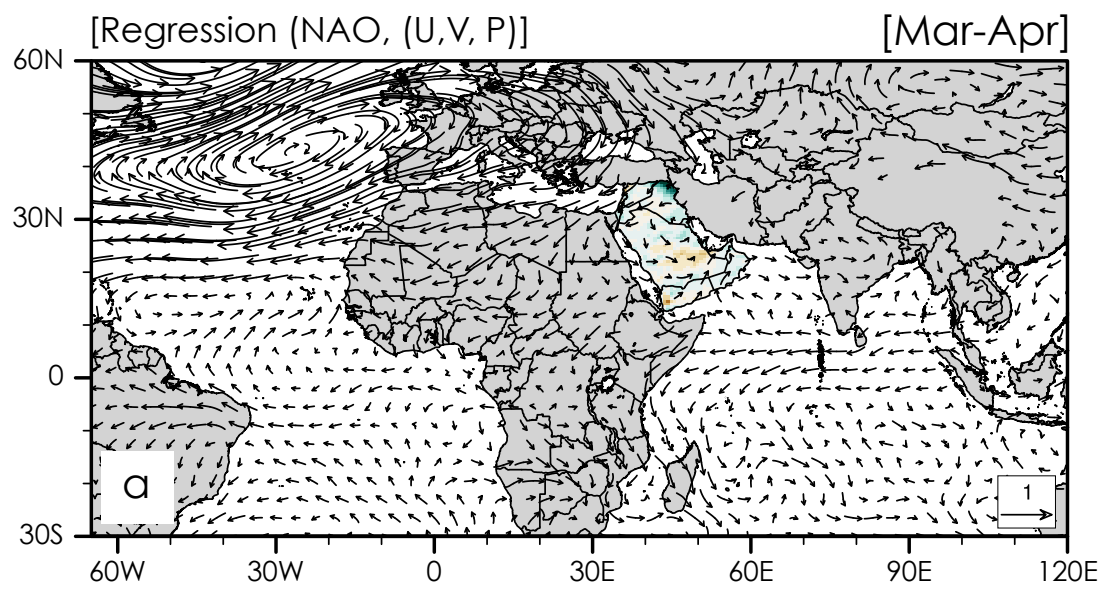

[Regression (NAO, P]

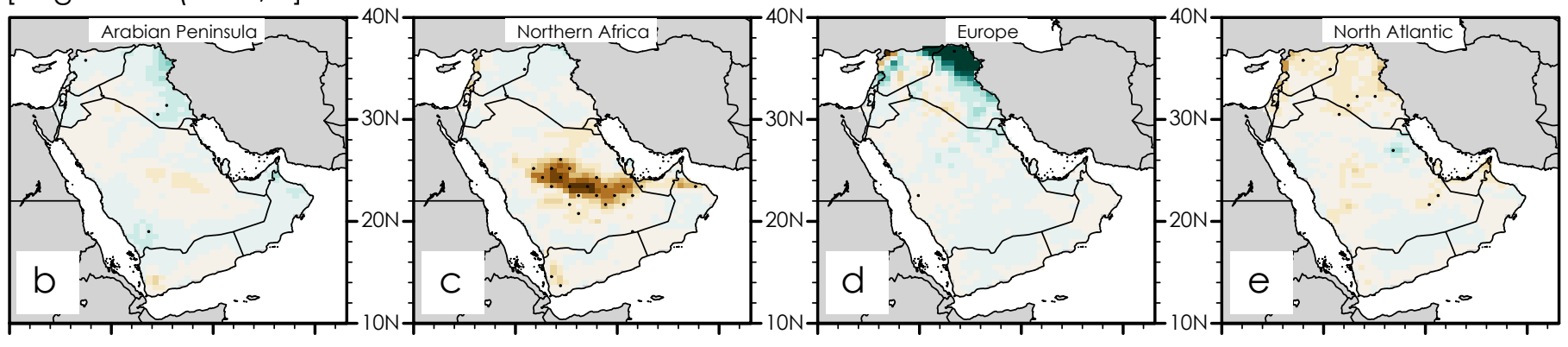

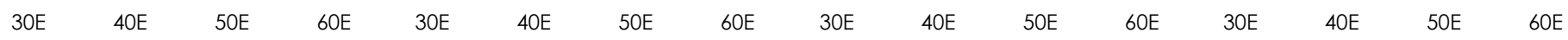
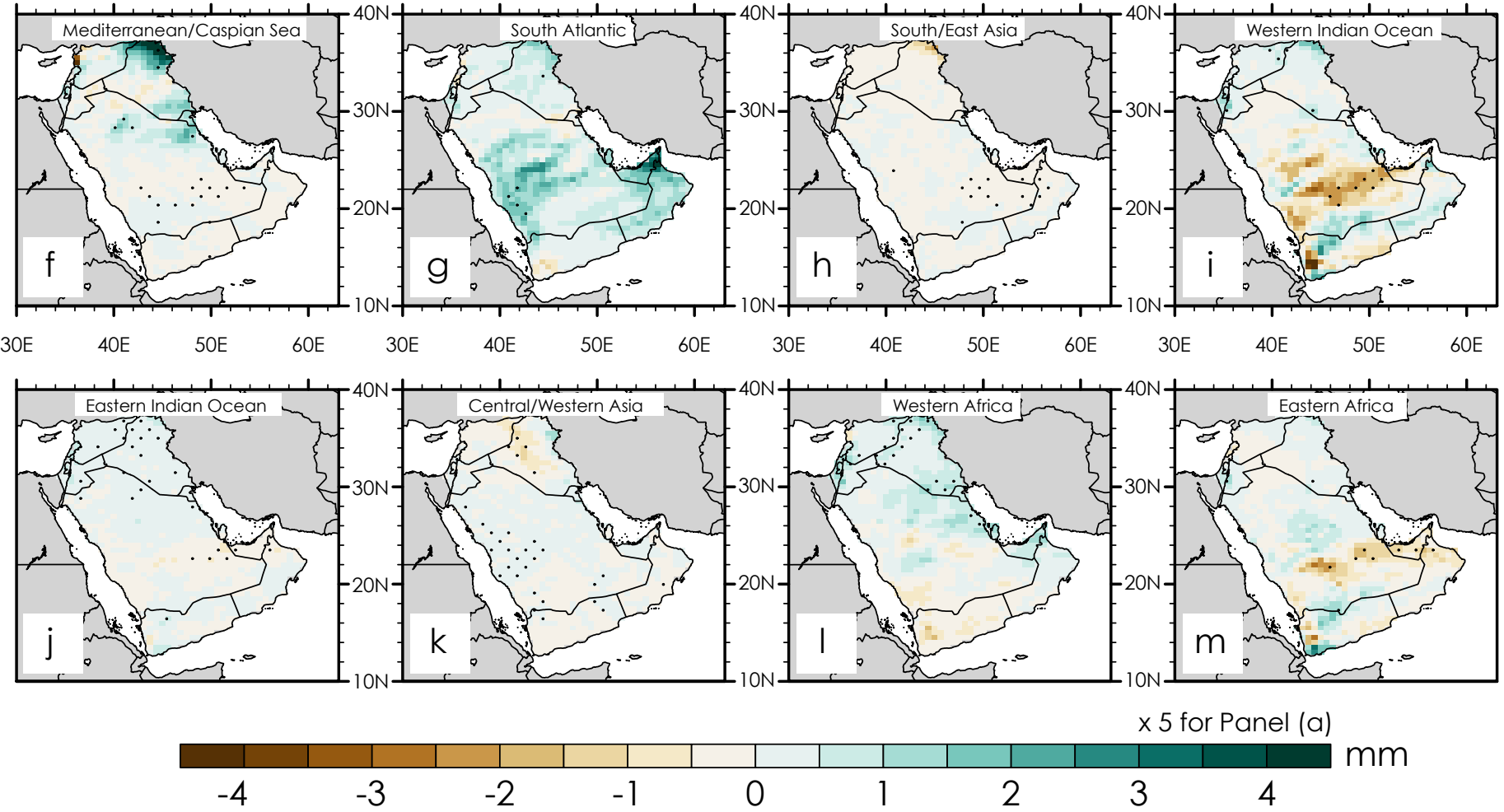

Figure S13. Same as in Figure S1 1 but for Mar-Apr. 
[Wet Season Precipitation Trends]
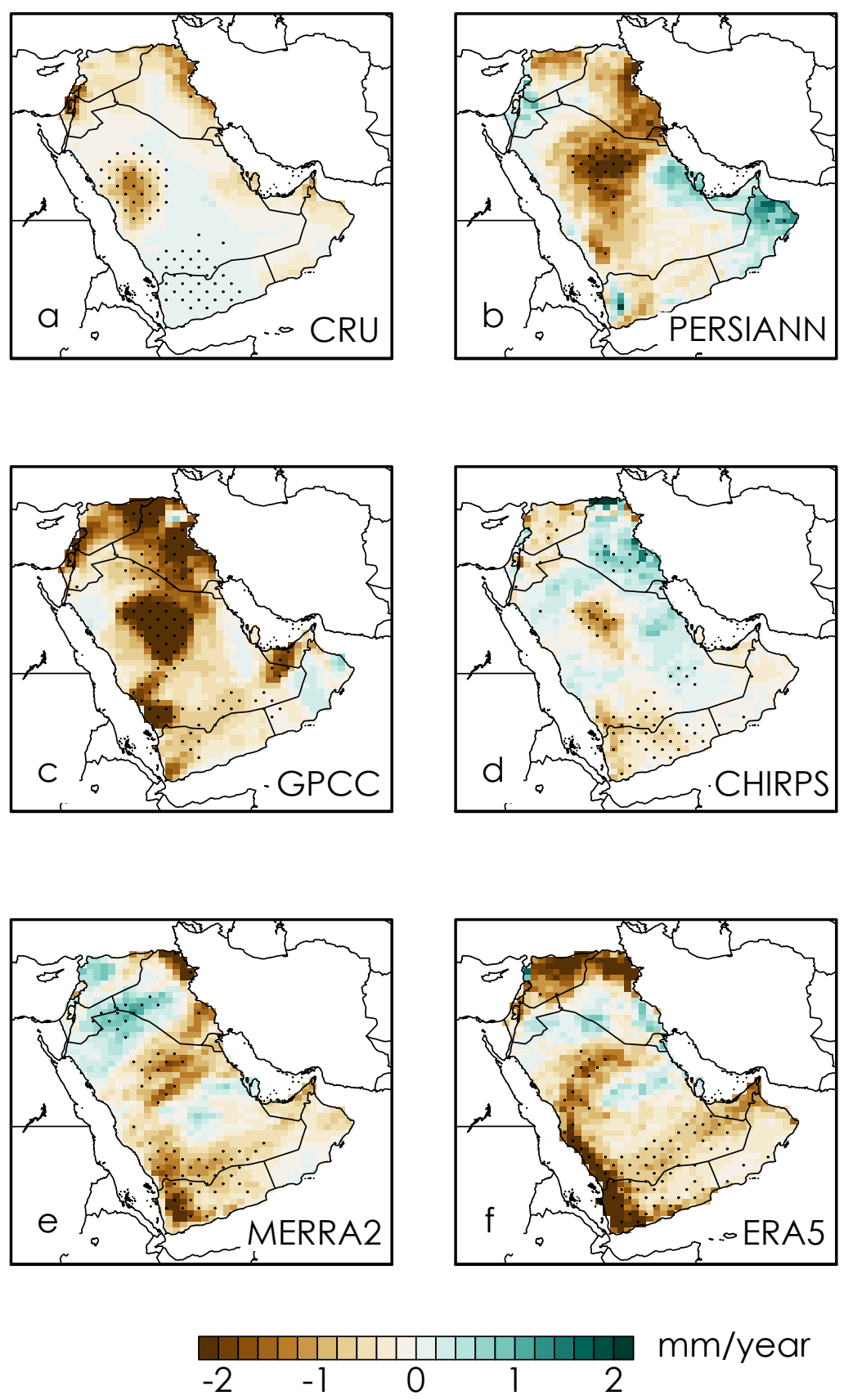

Figure S14. Seasonal accumulated precipitation trends (mm/year) during 1980-2019 in a) CRU, b) PERSIANN, c) GPCC, d) CHIRPS gridded observations and e) MERRA2, f) ERA5 reanalysis. Note that PERSIANN data was unavailable for 2017 through 2019 and GPCC data was unavailable for 1980 through 1982. Stippling indicates significance at $95 \%$ confidence level. 
[Wet Season Precipitation Trends]
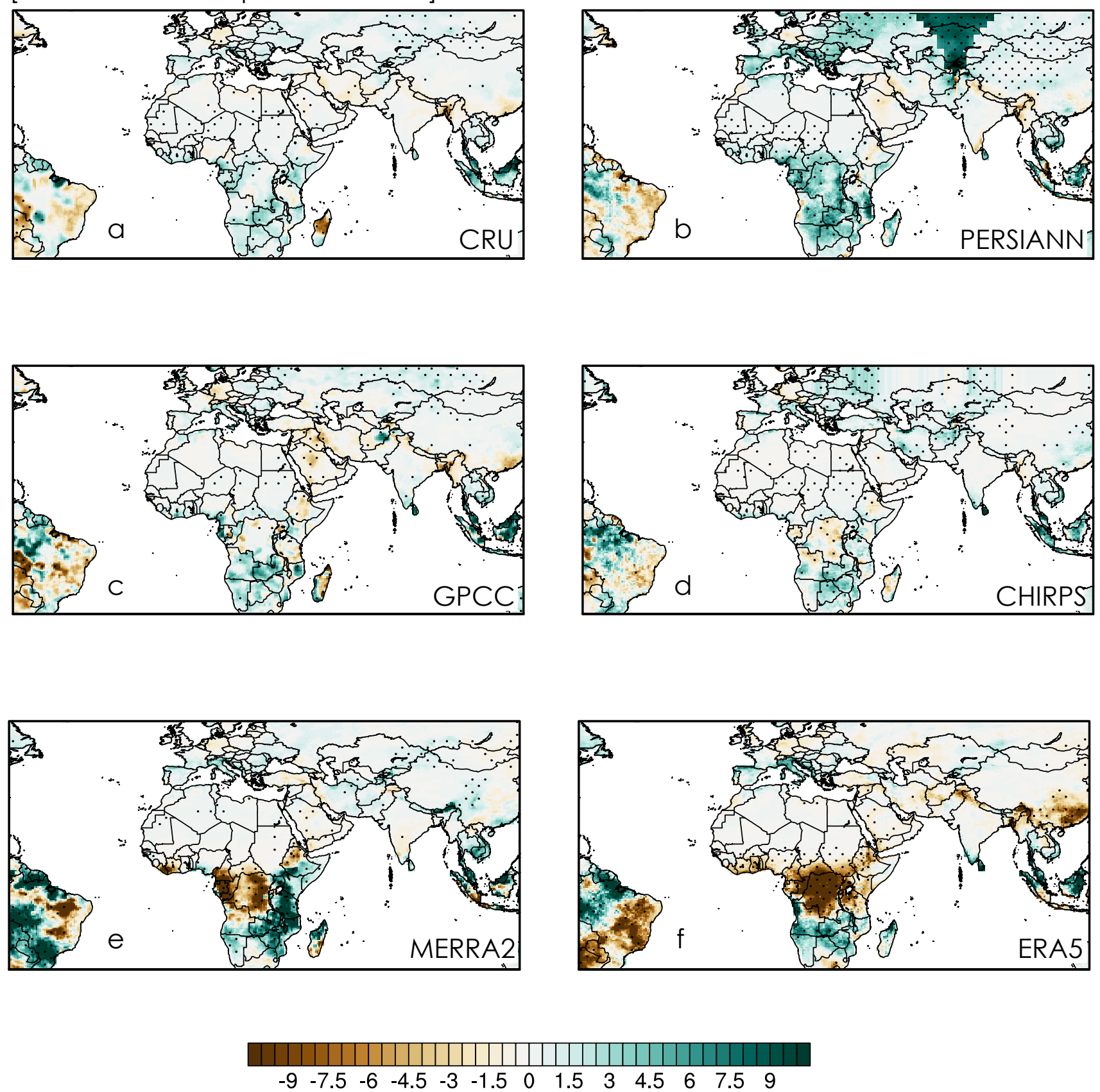

Figure S15. Same as in Figure S14 but for the whole evaporative source region. 
[Trends in Seasonal Contribution]
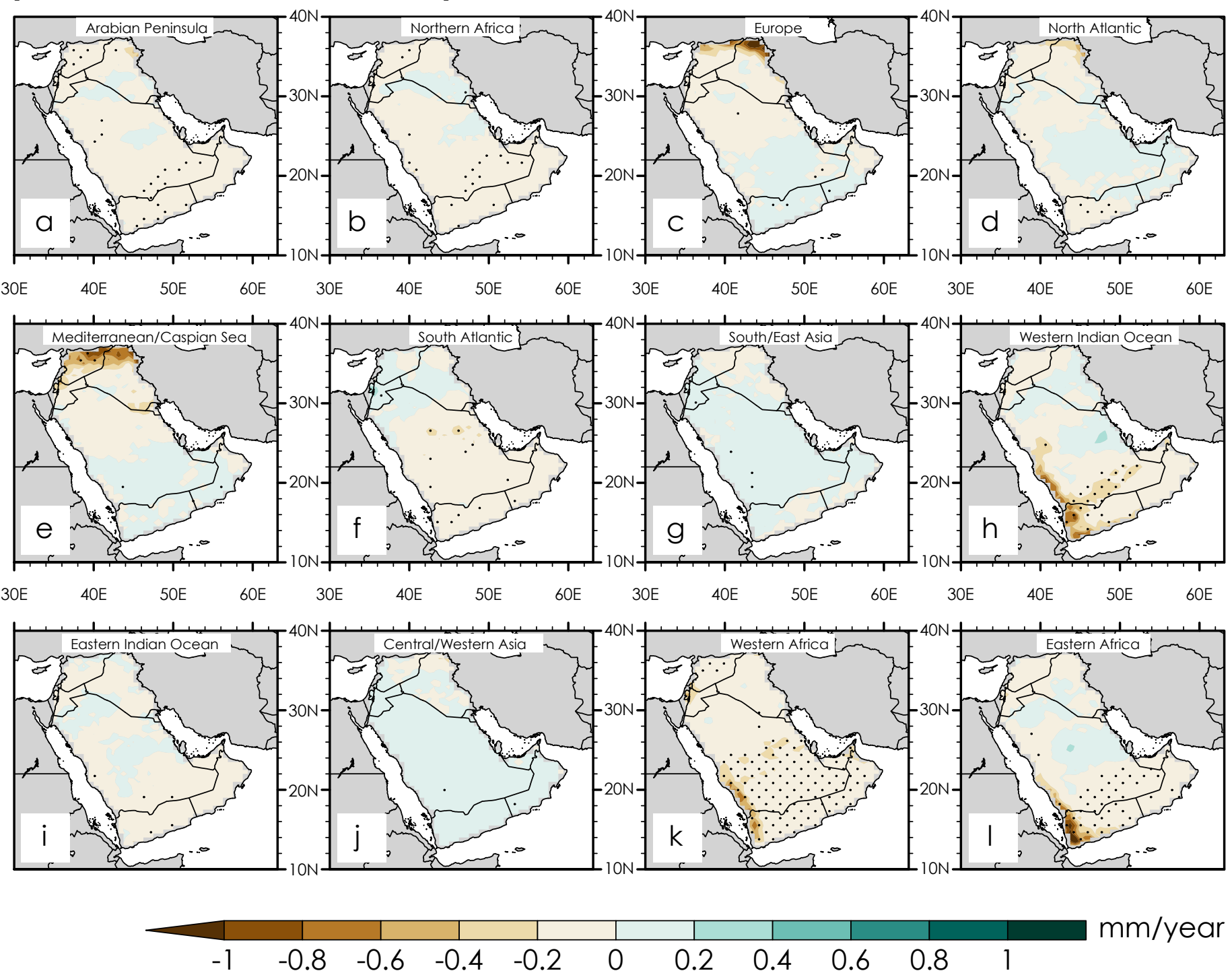

Figure S16. Trends ( $\mathrm{mm} / \mathrm{year}$ ) in seasonal accumulated contribution from each source region over 1980-2019 in ERA5. Stippling indicates significance at 95\% confidence level. 
[Trends in Seasonal Contribution]
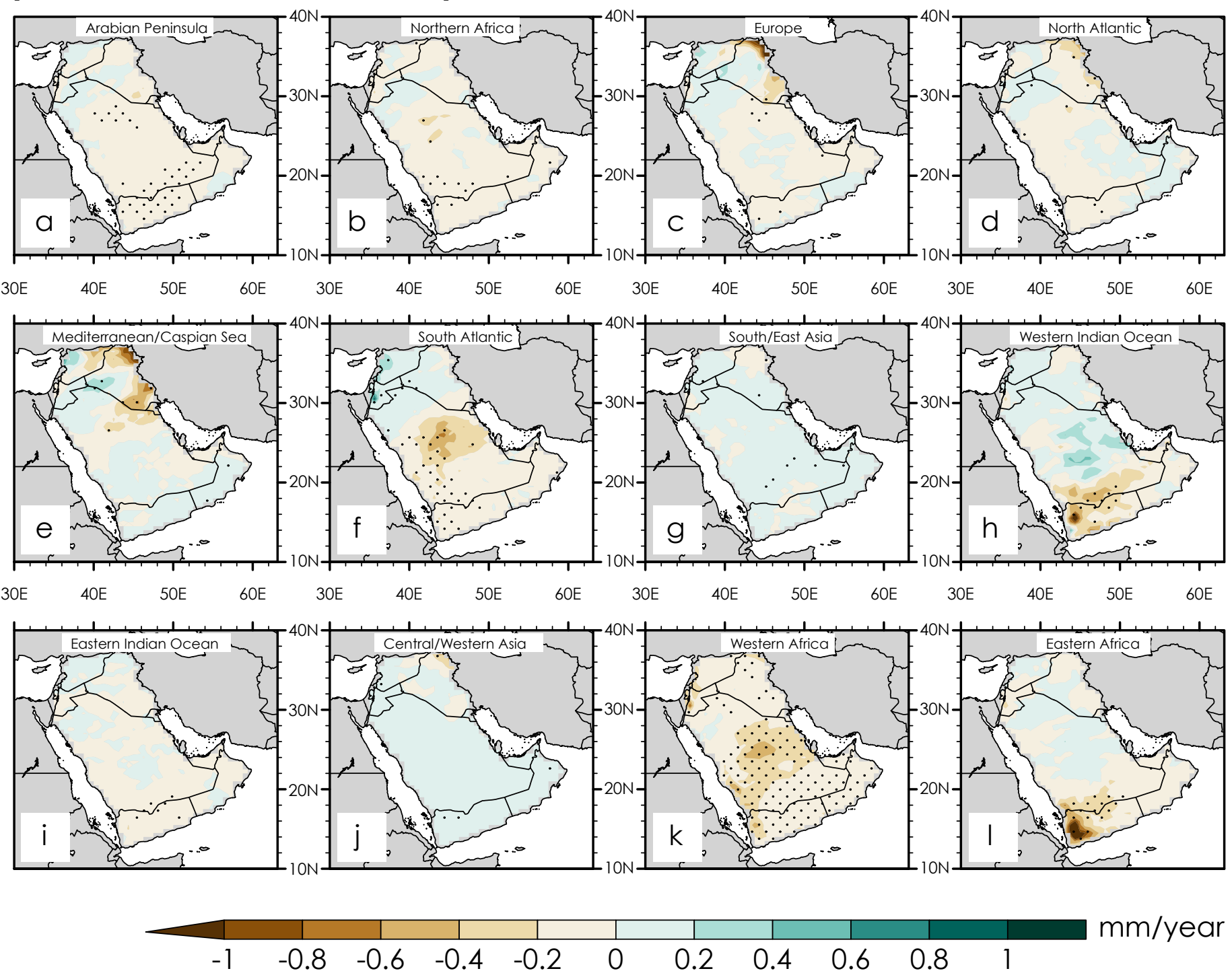

Figure S17. Trends ( $\mathrm{mm} / \mathrm{year}$ ) in seasonal accumulated contribution from each source region over 1980-2019 in MERRA2. Stippling indicates significance at 95\% confidence level. 